Supporting Information

\title{
Reaction Tracking and High-throughput Screening of Active Compounds in Combinatorial Chemistry by Tandem Mass Spectrometry Molecular Networking
}

Hsin-Hsiang Chung, ${ }^{[a]}$ Chih-Yao Kao, ${ }^{[a]}$ Tsung-Shing Andrew Wang, ${ }^{[a]}$ John Chu, ${ }^{[a]}$ Ji-Ying

Pei, ${ }^{*}[a, b]$ and Cheng-Chih Hsu*[a]

[a] Department of Chemistry, National Taiwan University, No. 1, Sec. 4, Roosevelt Rd., Taipei 10617, Taiwan

[b] School of Marine Sciences, Guangxi University, No.100, East Daxue Rd., Nanning City, Guangxi 530015, China.

Corresponding Author

*Email: ccrhsu@ntu.edu.tw (C. -C. Hsu)

*Email: pjying@gxu.edu.cn (J. -Y. Pei)

\section{Table of Contents}

1. Experimental procedures

2. Supporting tables

3. Supporting figures 


\section{Experimental procedures}

Chemicals and materials. All chemicals were commercial products of ACS grade and were used without any further purification.

Amino acids esterification reaction. The eight amino acids $(0.2 \mathrm{mmol}$ each) were dissolved in $8 \mathrm{~mL}$ of the alcohol mixtures (methanol, ethanol, 1-propanol, 1-butanol) (Scheme 1A). Trimethylsilyl chloride (TMSCl, $2 \mathrm{~mL}$ ) was added drop by drop to the solution to accelerate ester formation. The reaction mixture were stirred under room temperature for 36 hours. To track the reaction, we sampled at reaction time: $0 \mathrm{~min}, 5 \mathrm{~min}, 10 \mathrm{~min}, 30 \mathrm{~min}, 1$ hour, 2 hour, 4 hour, 8 hour, 12 hour, 20 hour, and 28 hour. After sampling, the samples were diluted 200 times using $5 \%$ acetonitrile $(A C N)$, and freezed using liquid nitrogen before analysis.

Ugi reaction. The two amines $(2.5 \mathrm{mmol}$ each), three aldehydes (1.67 mmol each), two isocyanides $(2.5 \mathrm{mmol}$ each), and seven carboxylic acids $(0.72 \mathrm{mmol}$ each) were added into methanol $(5 \mathrm{~mL})$ (Scheme 1B). The reaction mixture were stirred under room temperature for 36 hours. To track the reaction, we sampled at reaction time: 0 min, 10 min, 30 min, 1 hour, 2 hour, 4 hour, 8 hour, 12 hour, 20 hour, and 28 hour. After sampling, the samples were diluted 250 times using $30 \%$ acetonitrile (ACN), and freezed using liquid nitrogen before analysis.

\section{Preparation of mPro1.}

\section{3-Carboxybenzaldehyde dimethoxyacetal}

4-Carboxybenzaldehyde $(0.20 \mathrm{~g}, 1.33 \mathrm{mmol})$ and ammonium chloride $(0.40 \mathrm{~g}, 7.48 \mathrm{mmol})$ were heated under reflux in dry methanol (40 $\mathrm{mL}$ ) during $24 \mathrm{~h}$ under an atmosphere of nitrogen. The reaction mixture was filtered while warmed and the solvent was removed under reduced pressure to give a white solid. The product was purified by recrystallization from boiling dichloromethane $(0.24 \mathrm{~g}, 1.22 \mathrm{mmol}$, $92 \%)$.

\section{2. (S) N-(3-Dimethoxymethyl-benzoyl)-proline methyl ester}

L-Proline methyl ester hydrochloride $(0.21 \mathrm{~g}, 1.22 \mathrm{mmol})$ and 3-Carboxybenzaldehyde dimethoxyacetal $(0.24 \mathrm{~g}, 1.22 \mathrm{mmol})$ were dissolved in dry dichloromethane $(6.0 \mathrm{~mL})$ containing dry triethylamine $(0.34 \mathrm{~mL}, 2.44 \mathrm{mmol})$ under an atmosphere of nitrogen. The solution was cooled to $0 \mathrm{oC}$ on an ice bath then was added EDC $\cdot \mathrm{HCl}(0.23 \mathrm{~g}, 1.22 \mathrm{mmol})$ and DMAP $(0.0086 \mathrm{~g}, 0.070 \mathrm{mmol})$. The reaction mixture was stirred at $0 \mathrm{oC}$ for $1 \mathrm{~h}$ then was warm to room temperature and stirred for additional $12 \mathrm{~h}$. Dichloromethane $(50 \mathrm{~mL})$ was added into the reaction mixture before the subsequent washing of the organic phase with three portions of $\mathrm{H} 2 \mathrm{O}(30 \mathrm{~mL})$. The organic layer was dried over with $\mathrm{MgSO} 4$ and the solvent was removed under reduced pressure to give a yellow oil. The crude product was further purified by column chromatography ( $\mathrm{SiO} 2)$ [EtOAc/Hex, 8:2] yielded a colour-less oil $(0.27 \mathrm{~g}, 0.87 \mathrm{mmol}, 71 \%)$

\section{3. (S) N-(3-Dimethoxymethyl-benzoyl)-proline carboxylic acid hydrazide}

(S) N-(3-Dimethoxymethyl-benzoyl)-proline methyl ester $(0.12 \mathrm{~g}, 0.40 \mathrm{mmol})$ was dissolved in methanol $(4 \mathrm{~mL})$ then was treated with hydrazine monohydrate $(35 \%, 0.40 \mathrm{~mL}, 0.44 \mathrm{mmol})$. The solution was stirred for $20 \mathrm{~h}$ before removal of the solvent under reduced pressure to give a yellow oil. The crude product was further purified by flash column chromatography $\left(\mathrm{SiO}_{2}\right)\left[\mathrm{CH}_{2} \mathrm{Cl}_{2} / \mathrm{MeOH}^{2}, 9: 1\right]$ to afford a colour-less oil.

Pseudo-peptide DCC reaction. In the preparation of pseudo-peptide DCL, we followed the procedure published by Graham et al. ${ }^{1}$ The DCL was formed from the building block mPro 1. Two reactions were conducted with chloroform as solvent. For the first reaction, the $\mathrm{mPro} 1$ was mixed with one equivalent of trifluoroacetic acid (TFA). For the second reaction, the mPro 1 was mixed with one equivalent of trifluoroacetic acid (TFA) and acetylcholine (ACh). The reactions were stirred for 3 days to reach equilibrium under room temperature. The solvent was evaporated under reduced pressure. The products were then dissolved in $30 \%$ acetonitrile.

LC-MS/MS analysis. A Dionex UltiMate 3000 UHPLC system coupled with a $Q$ Exactive Plus hybrid quadruple-orbitrap mass spectrometer (Thermo Fisher Scientific, USA) was used for LC-MS/MS analysis. The mobile phase $\mathrm{A}$ and $\mathrm{B}$ were $\mathrm{H}_{2} \mathrm{O}$ with $0.1 \%$ formic acid and ACN with $0.1 \%$ formic acid respectively. The LC separation was performed using a binary gradient: mobile phase $A$ of water and mobile phase $B$ of $A C N$. Both $A$ and $B$ solvents contain $0.1 \%$ formic acid. The reaction mixture was separated using a $1.7 \mu$ m Acquity C18 column ( $2.1 \times 100 \mathrm{~mm}$, Waters, MA, USA) under $200 \mu \mathrm{L} / \mathrm{min}$ flow rate. The column temperature was set at $40{ }^{\circ} \mathrm{C}$. In the analysis of amino acid reaction, a 15-min gradient was established as: 0-2 min, 5\% B; 2-9 min, 5-65\% B; 9-9.5 min, 65-90\% B; 9.5-11.5 $\min , 90 \% \mathrm{~B} ; 11.5-12 \mathrm{~min}, 90-5 \% \mathrm{~B} ; 12-15 \mathrm{~min}, 5 \% \mathrm{~B}$. In the analysis of Ugi reaction, a 30-min gradient was established as: $0-2 \mathrm{~min}$ $30 \% \mathrm{~B} ; 2-20 \mathrm{~min}, 30-90 \% \mathrm{~B} ; 20-25 \mathrm{~min}, 90 \% \mathrm{~B} ; 25-26 \mathrm{~min}, 90-30 \% \mathrm{~B} ; 26-30 \mathrm{~min}, 30 \% \mathrm{~B}$. In the analysis of pseudo-peptide DCC reaction, a 25-min gradient was established as: 0-2 min, 5\% B; 2-16 min, 5-99\% B; 16-21 min, 99\% B; 21-22 min, 99-5\% B; 22-25 min, $5 \% \mathrm{~B}$. Thermo HESI probe was used as the ion source, and the spray voltage was set at $+3.5 \mathrm{kV}$. For full scan acquisition, the mass range was from $\mathrm{m} / \mathrm{z} 100$ to 1,000 , from $\mathrm{m} / \mathrm{z} 150$ to 550 , from $\mathrm{m} / \mathrm{z} 140$ to 2,000 for amino acid reaction, Ugi reaction, and DCC reaction, respectively. The resolution of full scan was set at 35,000. A top 10 data-dependent acquisition (DDA) was performed to collect the MS/MS spectrum. The normalized higher-energy collisional dissociation (HCD) energy was set at $25 \%, 20 \%$, and $30 \%$ for amino acid esterification, Ugi reaction, and pseudo-peptide reaction, respectively. The MS/MS spectra were acquired with the resolution of 17,500.

GNPS molecular networking parameters setting. The molecular networks were created using the online workflow (https://ccmsucsd.github.io/GNPSDocumentation/) on the GNPS website (http://gnps.ucsd.edu). The LC-MS/MS data was first converted into mzXML format using MSConvert, ${ }^{2}$ and uploaded to Global Natural Products Social (GNPS) for data processing. ${ }^{3}$ For amino acid esterification reaction, the data was clustered with MS-Cluster with a parent mass tolerance of $0.005 \mathrm{Da}$ and a MS/MS fragment ion tolerance of $0.01 \mathrm{Da}$ to create consensus spectra. Further, concensus spectra that contained less than 1 spectra were discarded. A network was then created where edges were filtered to have a cosine score above 0.6 and more than 2 matched peaks. Further edges between two nodes were kept in the network if and only if each of the nodes appeared in each other's respective top 10 most similar 
nodes. Peaks with intensity under 10000 were filtered. For the Ugi reaction, the data was clustered with MS-Cluster with a parent mass tolerance of $0.005 \mathrm{Da}$ and a MS/MS fragment ion tolerance of $0.01 \mathrm{Da}$ to create consensus spectra. Further, concensus spectra that contained less than 1 spectra were discarded. A network was then created where edges were filtered to have a cosine score above 0.5 and more than 2 matched peaks. Further edges between two nodes were kept in the network if and only if each of the nodes appeared in each other's respective top 20 most similar nodes. Peaks with intensity under 6000 were filtered. For the pseudo-peptide DCC reaction, the precursor ion mass tolerance was set to $0.005 \mathrm{Da}$ and a MS/MS fragment ion tolerance of $0.005 \mathrm{Da}$. A network was then created where edges were filtered to have a cosine score above 0.8 and more than 4 matched peaks. Further, edges between two nodes were kept in the network if and only if each of the nodes appeared in each other's respective top 10 most similar nodes. Peaks with intensity under 10000 were filtered. For all the three molecular networks, the maximum size of a molecular family was set to 100, and the lowest scoring edges were removed from molecular families until the molecular family size was below this threshold. The output files were then visualized using Cytoscape_v3.6.0.4 The molecular network of Figure 2C and Figure 2D can be visualized directly on GNPS via the following link: _https://gnps.ucsd.edu/ProteoSAFe/status.jsp?task=7fb576a2dff84f65be4795569e92015a and https://gnps.ucsd.edu/ProteoSAFe/status.jsp?task=45d4aba36a3948e1832fb411d04be862, respectively. The MS/MS of the products of amino acid esterification and Ugi combinatorial synthesis can be found in the following library: https://gnps.ucsd.edu/ProteoSAFe/result.jsp?task=00ccdd84adb34d748b86da4f48c46bb7\&view=group new annotations db.

Time-dependent molecular networking analysis. The Matlab based GUI called time-dependent molecular networking was used to track the intensity of each node at different time points, ${ }^{5}$ and could be downloaded from https://drive.google.com/file/d/1mnYPeUccv7uoNOUjBUIn6kS94P2jMvPh/view. The result files from the GNPS as well as LC-MS/MS data of different reaction time were imported into time-dependent molecular networking. The $\mathrm{m} / \mathrm{z}$ tolerance was set as $0.1 \mathrm{Da}$, with time limit of 3 times of retention time standard deviation. The result files were then inputted into Cytoscape_v3.6.0. The intensity of each node was represented using the size of the node. The molecular network of Figure 4 can be visualized directly on GNPS via the following link: https://gnps.ucsd.edu/ProteoSAFe/status.jsp?task=39546e257ac4425eb0b6357a8e0b0479.

\section{References}

(1) Cousins, G. R. L.; Furlan, R. L. E.; Ng, Y.-F.; Redman, J. E.; Sanders, J. K. M., Identification and Isolation of a Receptor for N-Methyl Alkylammonium Salts: Molecular Amplification in a Pseudo-peptide Dynamic Combinatorial Library. Angew. Chem. Int. Ed. 2001, 40 (2), 423-428.

(2) Chambers, M. C.; Maclean, B.; Burke, R.; Amodei, D.; Ruderman, D. L.; Neumann, S.; Gatto, L.; Fischer, B.; Pratt, B.; Egertson, J.; Hoff, K.; Kessner, D.; Tasman, N.; Shulman, N.; Frewen, B.; Baker, T. A.; Brusniak, M.-Y.; Paulse, C.; Creasy, D.; Flashner, L.; Kani, K.; Moulding, C.; Seymour, S. L.; Nuwaysir, L. M.; Lefebvre, B.; Kuhlmann, F.; Roark, J.; Rainer, P.; Detlev, S.; Hemenway, T.; Huhmer, A.; Langridge, J.; Connolly, B.; Chadick, T.; Holly, K.; Eckels, J.; Deutsch, E. W.; Moritz, R. L.; Katz, J. E.; Agus, D. B.; MacCoss, M.; Tabb, D. L.; Mallick, P., A cross-platform toolkit for mass spectrometry and proteomics. Nat. Biotechnol. 2012, 30 (10), 918-920.

(3) Wang, M.; Carver, J. J.; Phelan, V. V.; Sanchez, L. M.; Garg, N.; Peng, Y.; Nguyen, D. D.; Watrous, J.; Kapono, C. A.; Luzzatto-Knaan, T.; Porto, C.; Bouslimani, A.; Melnik, A. V.; Meehan, M. J.; Liu, W.-T.; Crüsemann, M.; Boudreau, P. D.; Esquenazi, E.; Sandoval-Calderón, M.; Kersten, R. D.; Pace, L. A.; Quinn, R. A.; Duncan, K. R.; Hsu, C.-C.; Floros, D. J.; Gavilan, R. G.; Kleigrewe, K.; Northen, T.; Dutton, R. J.; Parrot, D.; Carlson, E. E.; Aigle, B.; Michelsen, C. F.; Jelsbak, L.; Sohlenkamp, C.; Pevzner, P.; Edlund, A.; McLean, J.; Piel, J.; Murphy, B. T.; Gerwick, L.; Liaw, C.-C.; Yang, Y.-L.; Humpf, H.-U.; Maansson, M.; Keyzers, R. A.; Sims, A. C.; Johnson, A. R.; Sidebottom, A. M.; Sedio, B. E.; Klitgaard, A.; Larson, C. B.; Boya P, C. A.; Torres-Mendoza, D.; Gonzalez, D. J.; Silva, D. B.; Marques, L. M.; Demarque, D. P.; Pociute, E.; O'Neill, E. C.; Briand, E.; Helfrich, E. J. N.; Granatosky, E. A.; Glukhov, E.; Ryffel, F.; Houson, H.; Mohimani, H.; Kharbush, J. J.; Zeng, Y.; Vorholt, J. A.; Kurita, K. L.; Charusanti, P.; McPhail, K. L.; Nielsen, K. F.; Vuong, L.; Elfeki, M.; Traxler, M. F.; Engene, N.; Koyama, N.; Vining, O. B.; Baric, R.; Silva, R. R.; Mascuch, S. J.; Tomasi, S.; Jenkins, S.; Macherla, V.; Hoffman, T.; Agarwal, V.; Williams, P. G.; Dai, J.; Neupane, R.; Gurr, J.; Rodríguez, A. M. C.; Lamsa, A.; Zhang, C.; Dorrestein, K.; Duggan, B. M.; Almaliti, J.; Allard, P.-M.; Phapale, P.; Nothias, L.-F.; Alexandrov, T.; Litaudon, M.; Wolfender, J.-L.; Kyle, J. E.; Metz, T. O.; Peryea, T.; Nguyen, D.-T.; VanLeer, D.; Shinn, P.; Jadhav, A.; Müller, R.; Waters, K. M.; Shi, W.; Liu, X.; Zhang, L.; Knight, R.; Jensen, P. R.; Palsson, B. Ø.; Pogliano, K.; Linington, R. G.; Gutiérrez, M.; Lopes, N. P.; Gerwick, W. H.; Moore, B. S.; Dorrestein, P. C.; Bandeira, N., Sharing and community curation of mass spectrometry data with Global Natural Products Social Molecular Networking. Nat. Biotechnol. 2016, 34 (8), 828-837.

(4) Shannon, P.; Markiel, A.; Ozier, O.; Baliga, N. S.; Wang, J. T.; Ramage, D.; Amin, N.; Schwikowski, B.; Ideker, T., Cytoscape: a software environment for integrated models of biomolecular interaction networks. Genome Res. 2003, 13 (11), $2498-2504$.

(5) Gao, Y.-L.; Wang, Y.-J.; Chung, H.-H.; Chen, K.-C.; Shen, T.-L.; Hsu, C.-C., Molecular networking as a dereplication strategy for monitoring metabolites of natural product treated cancer cells. Rapid Commun. Mass Spectrom. 2020, 34 (S1), e8549. 


\section{Supporting tables}

Table S1. The product list for amino acid esterification reaction.

\begin{tabular}{|c|c|c|c|c|c|}
\hline ID & Structure & {$[\mathrm{M}+\mathrm{H}]^{+}$} & ID & Structure & {$[\mathrm{M}+\mathrm{H}]^{+}$} \\
\hline A-1 & & 147.077 & $E-1$ & & 196.097 \\
\hline A-2 & & 161.093 & $E-2$ & & 210.113 \\
\hline A-3 & & 175.108 & $E-3$ & & 224.129 \\
\hline A-4 & & 189.124 & $E-4$ & & 238.144 \\
\hline B-1 & & 164.074 & F-1 & & 219.113 \\
\hline B-2 & & 178.090 & $F-2$ & & 233.129 \\
\hline B-3 & & 192.106 & $F-3$ & & 247.145 \\
\hline
\end{tabular}




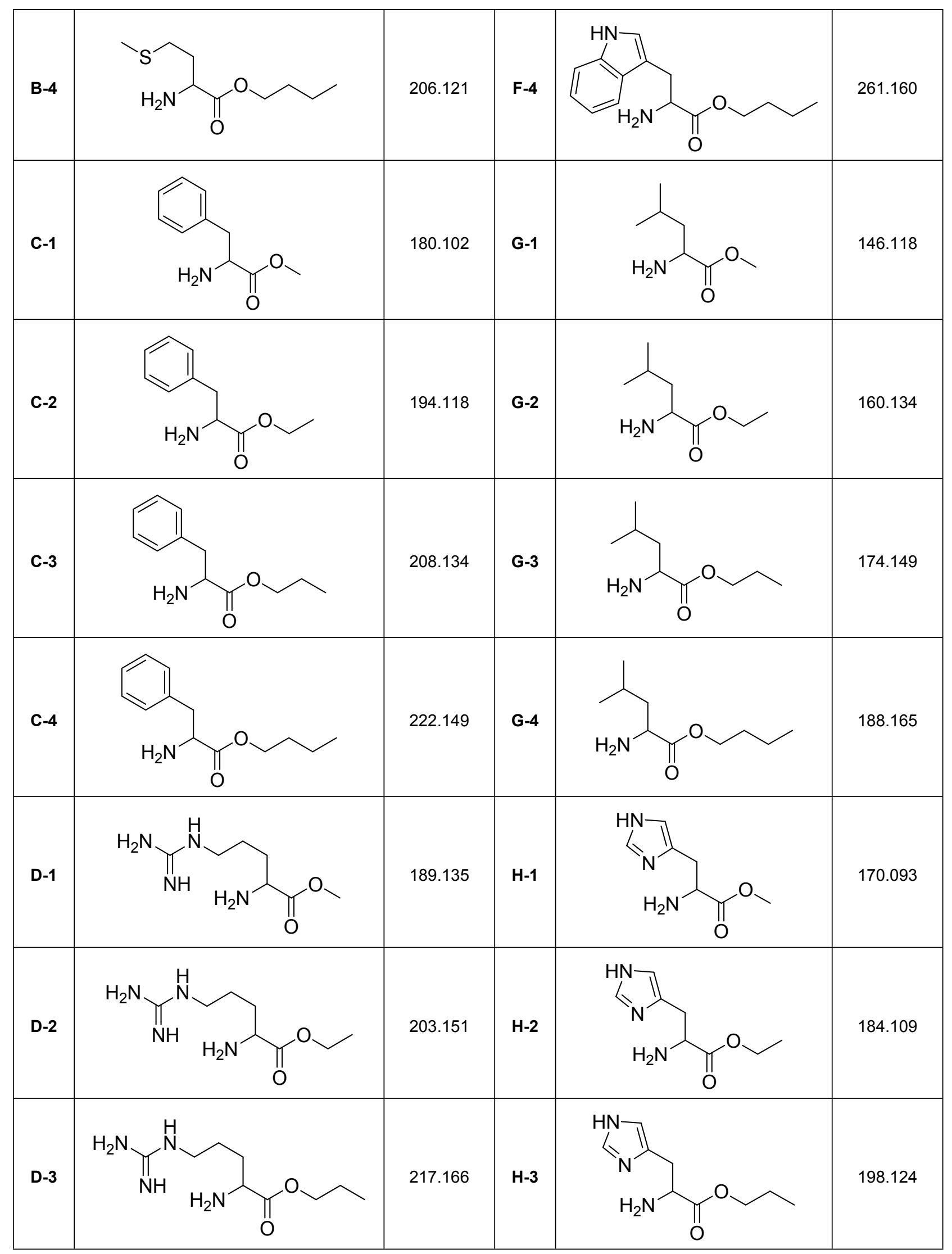




(2)


Table S2. The product list for Ugi reaction.

\begin{tabular}{|c|c|c|c|c|c|}
\hline ID & Structure & {$[\mathrm{M}+\mathrm{H}]^{+}$} & ID & Structure & {$[\mathrm{M}+\mathrm{H}]^{+}$} \\
\hline I-i-a-5 & & 269.223 & II-i-a-5 & & 277.192 \\
\hline I-i-a-6 & & 283.238 & II-i-a-6 & & 291.207 \\
\hline I-i-a-7 & & 297.254 & II-i-a-7 & & 305.223 \\
\hline I-i-a-8 & & 311.270 & II-i-a-8 & & 319.238 \\
\hline I-i-a-9 & & 325.285 & II-i-a-9 & & 333.254 \\
\hline I-i-a-10 & & 339.301 & II-i-a-10 & & 347.270 \\
\hline I-i-a-11 & & 309.254 & II-i-a-11 & & 317.223 \\
\hline I-i-b-5 & & 347.233 & II-i-b-5 & & 355.202 \\
\hline I-i-b-6 & & 361.249 & II-i-b-6 & & 369.218 \\
\hline
\end{tabular}




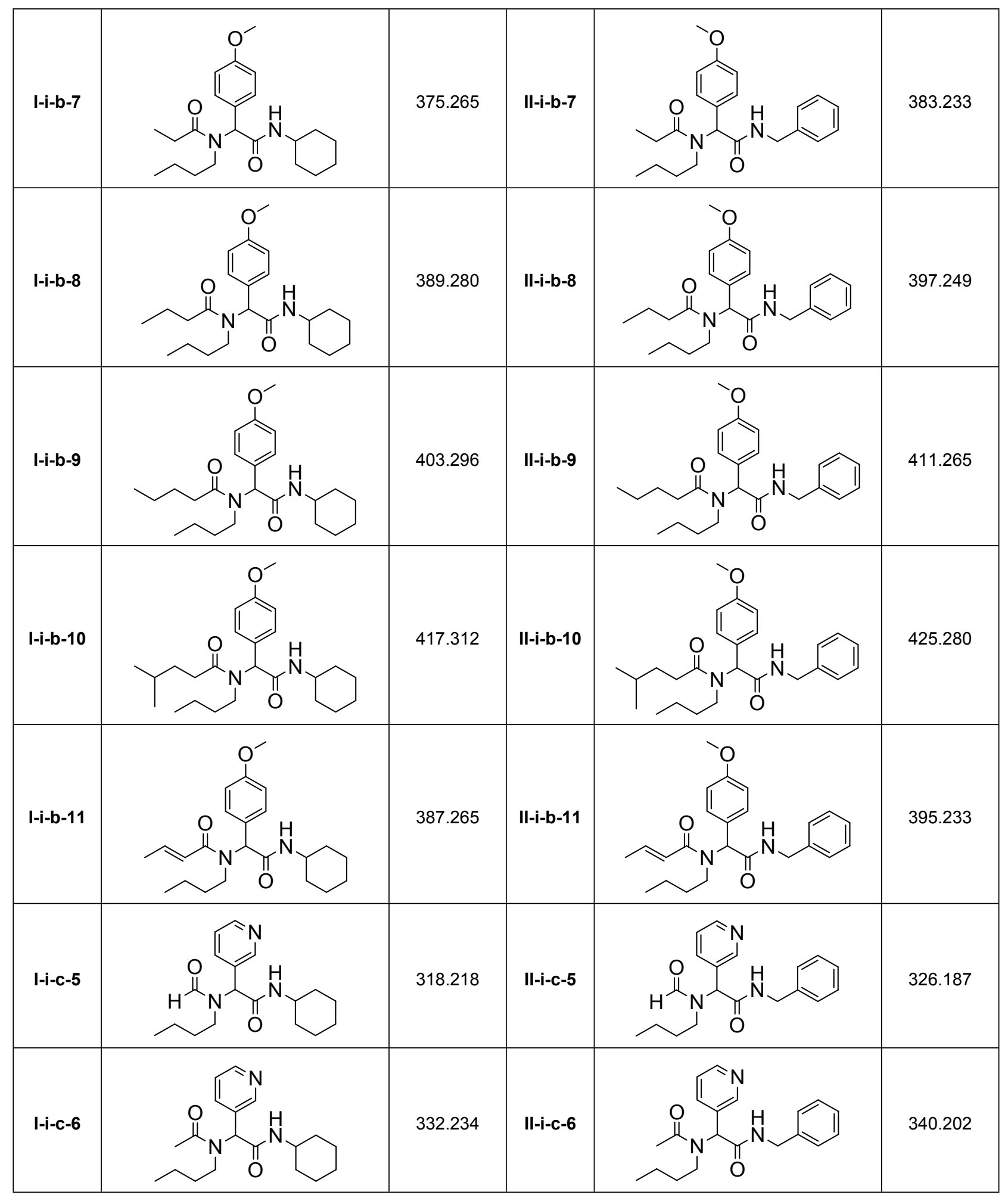




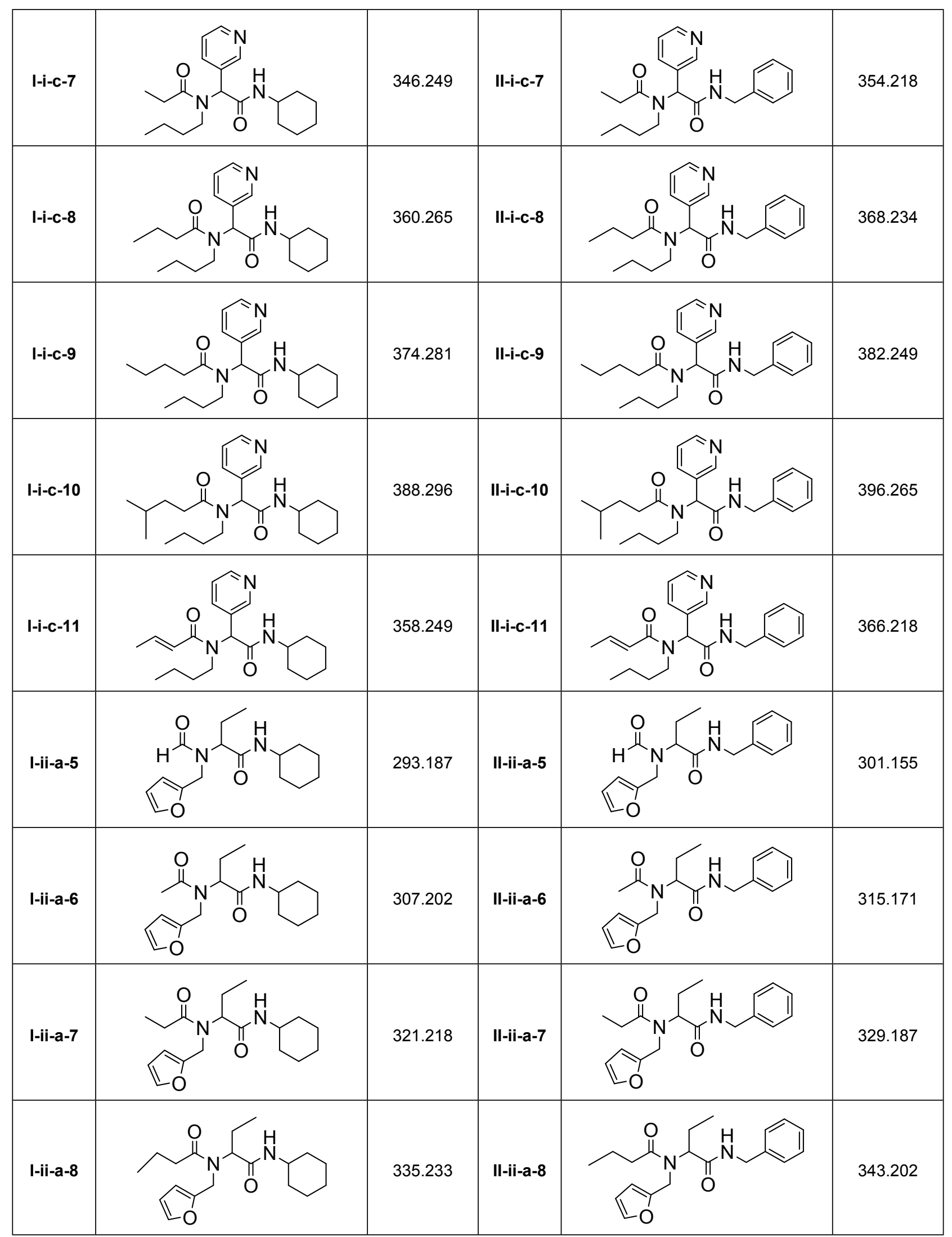




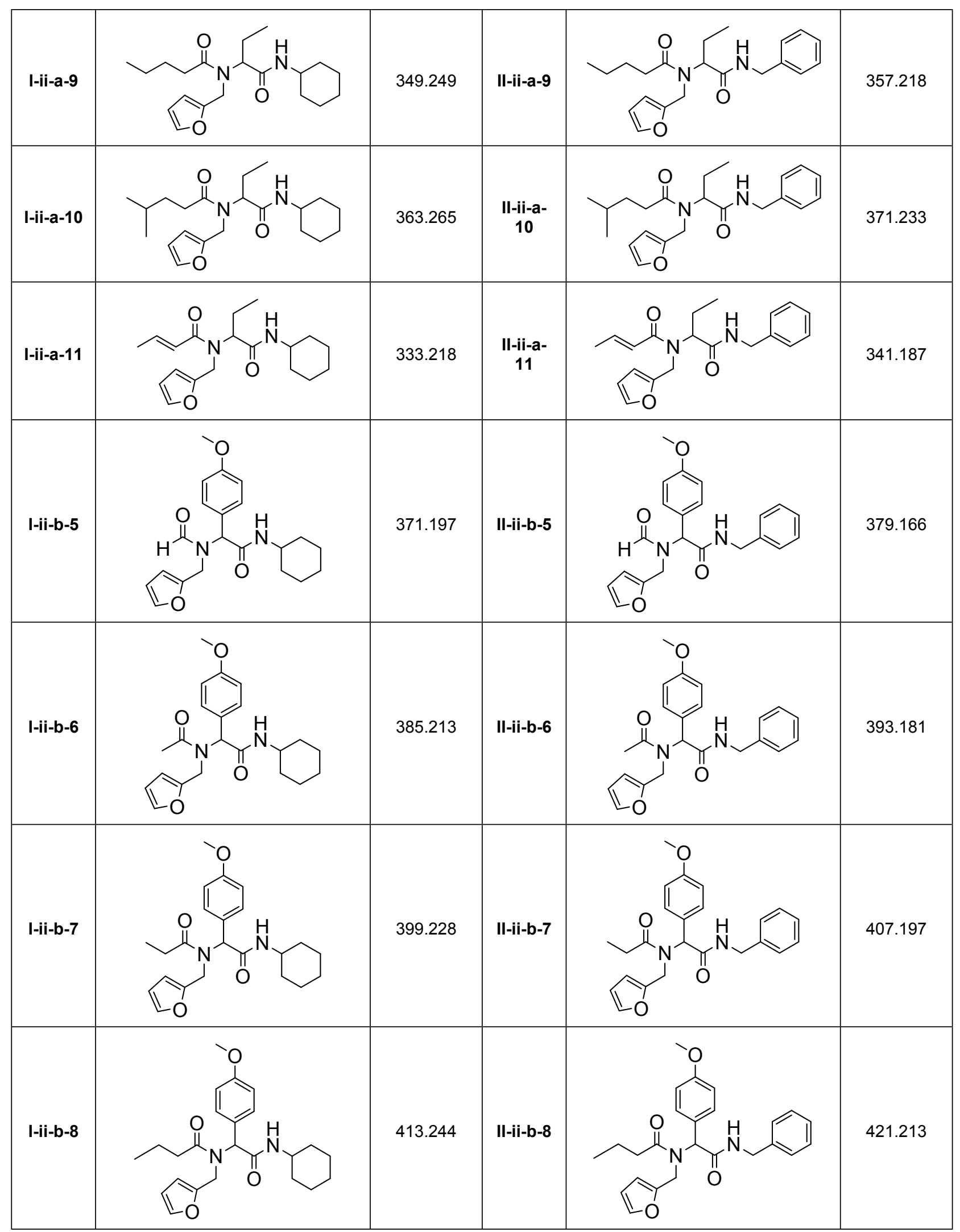




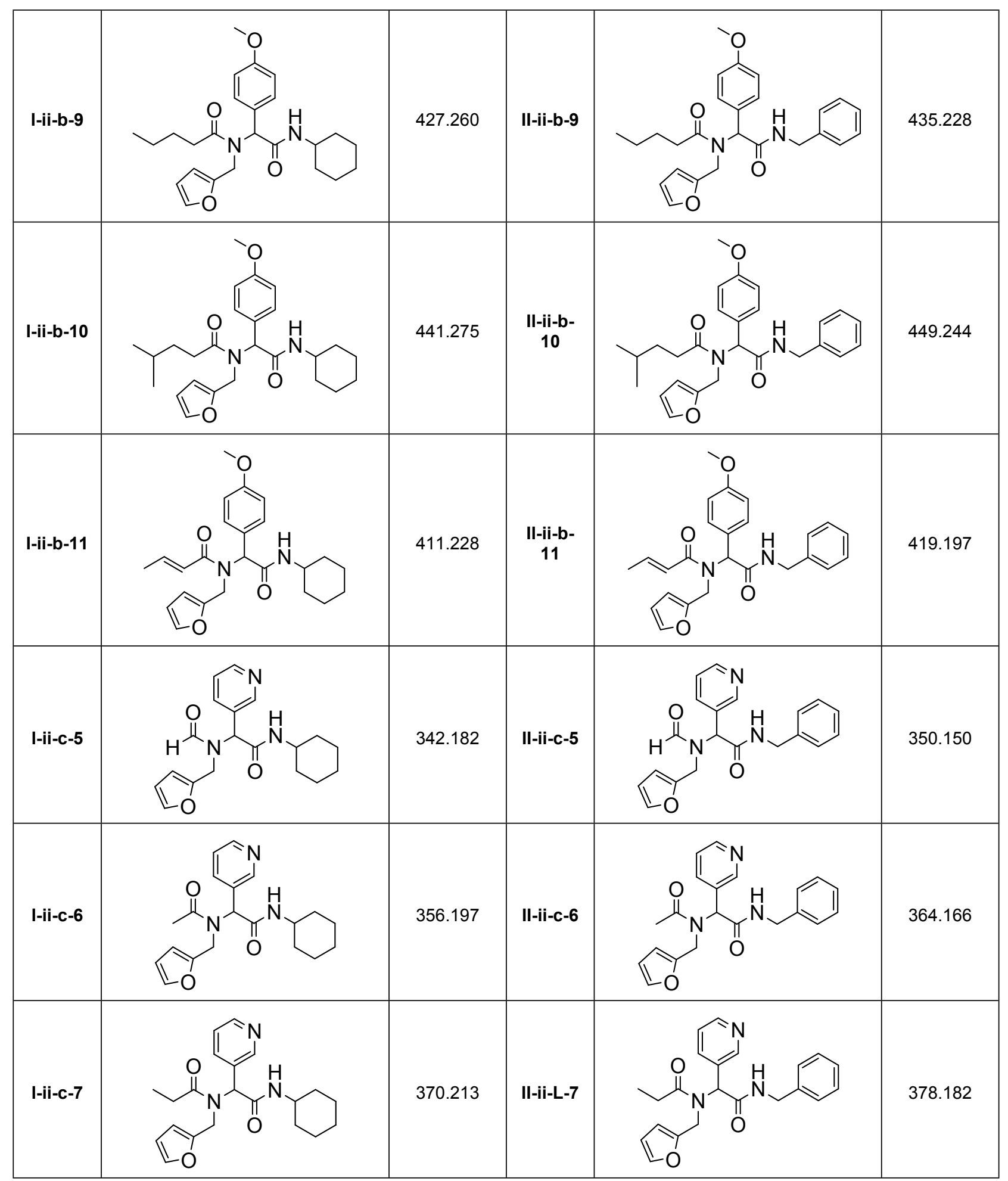




(1)




\section{Supporting figures}

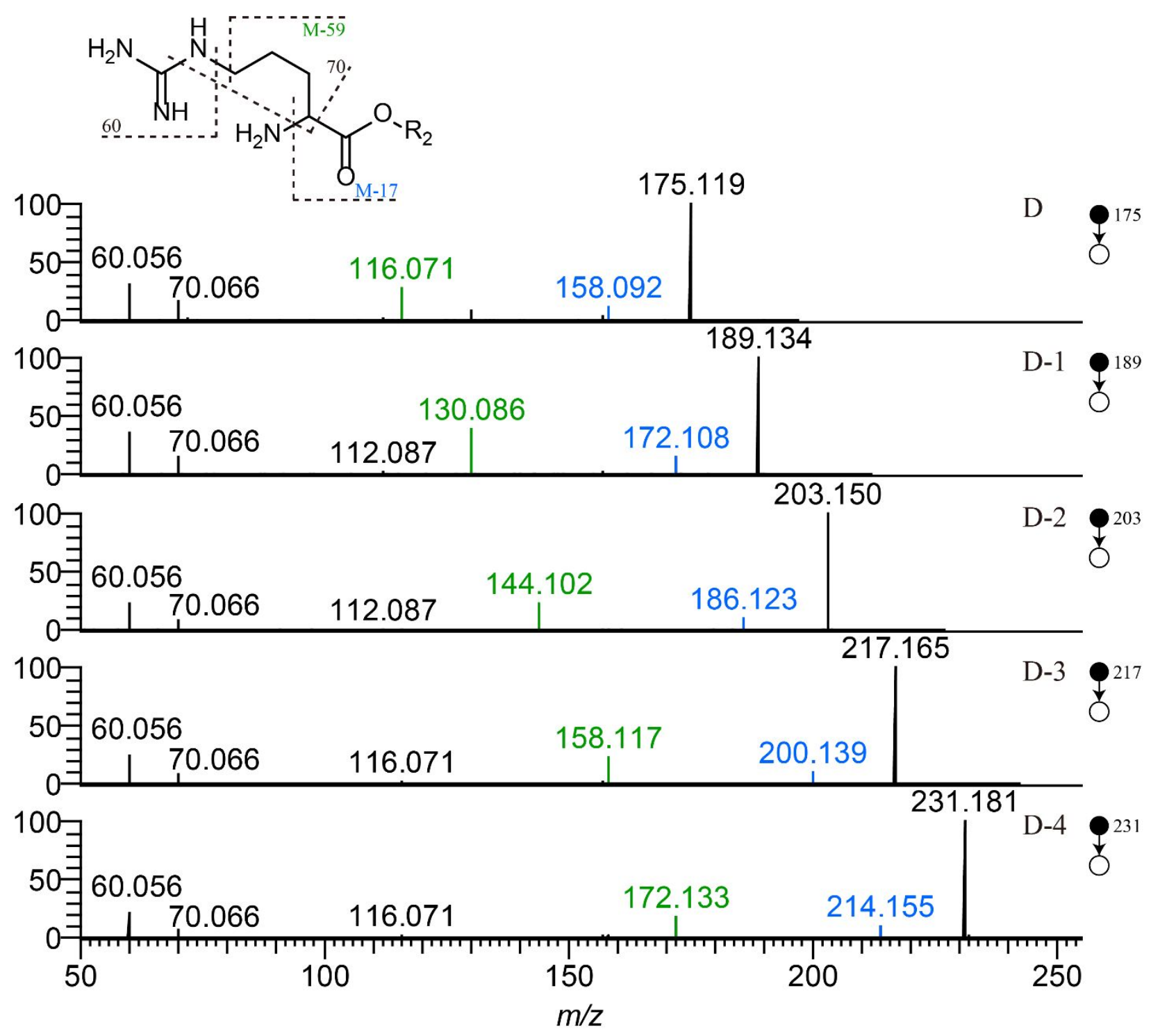

Figure S1. The structures of the fragment ions of products D-P2. 


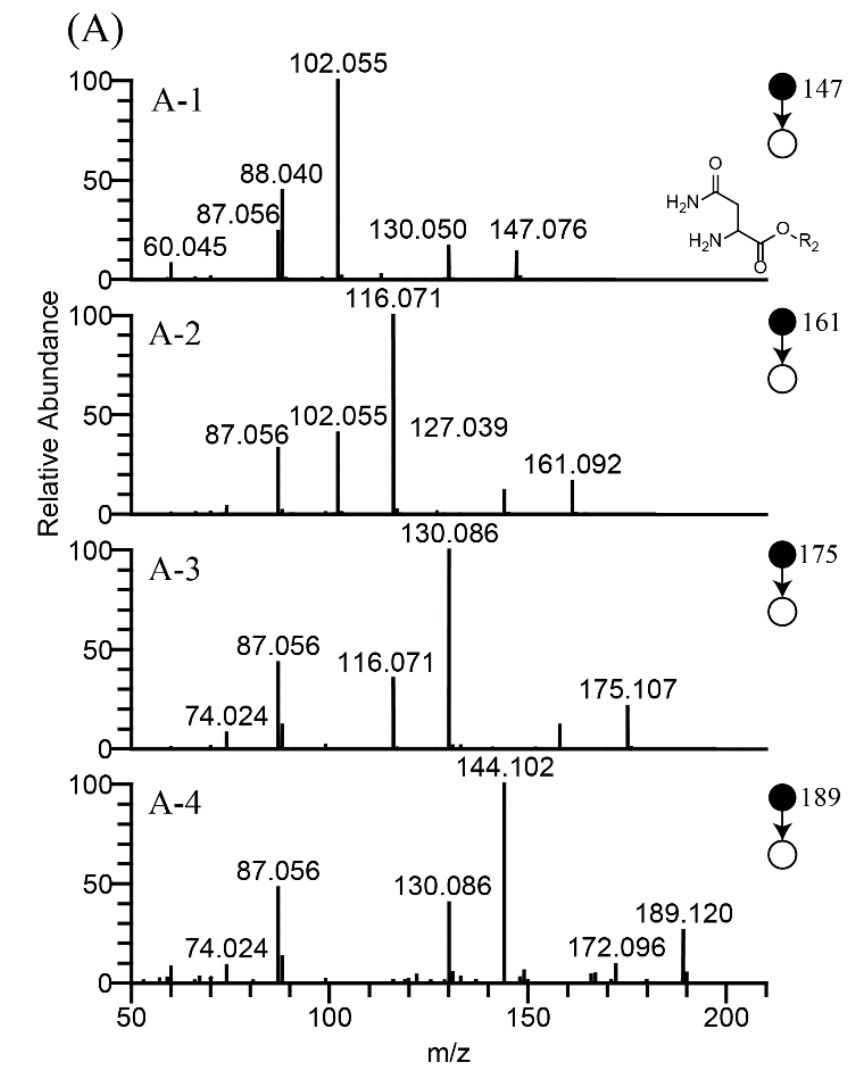

(B)
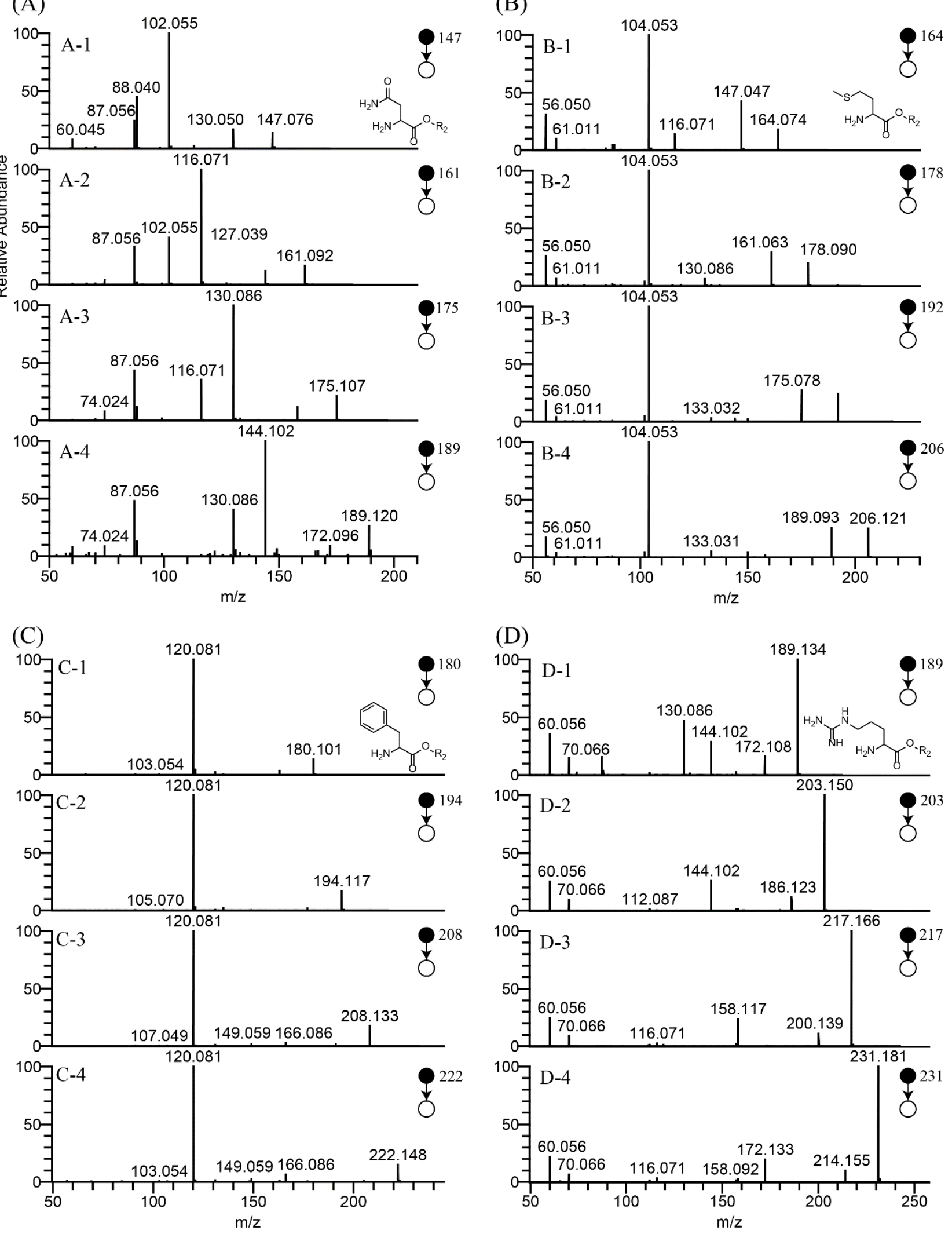
(E)

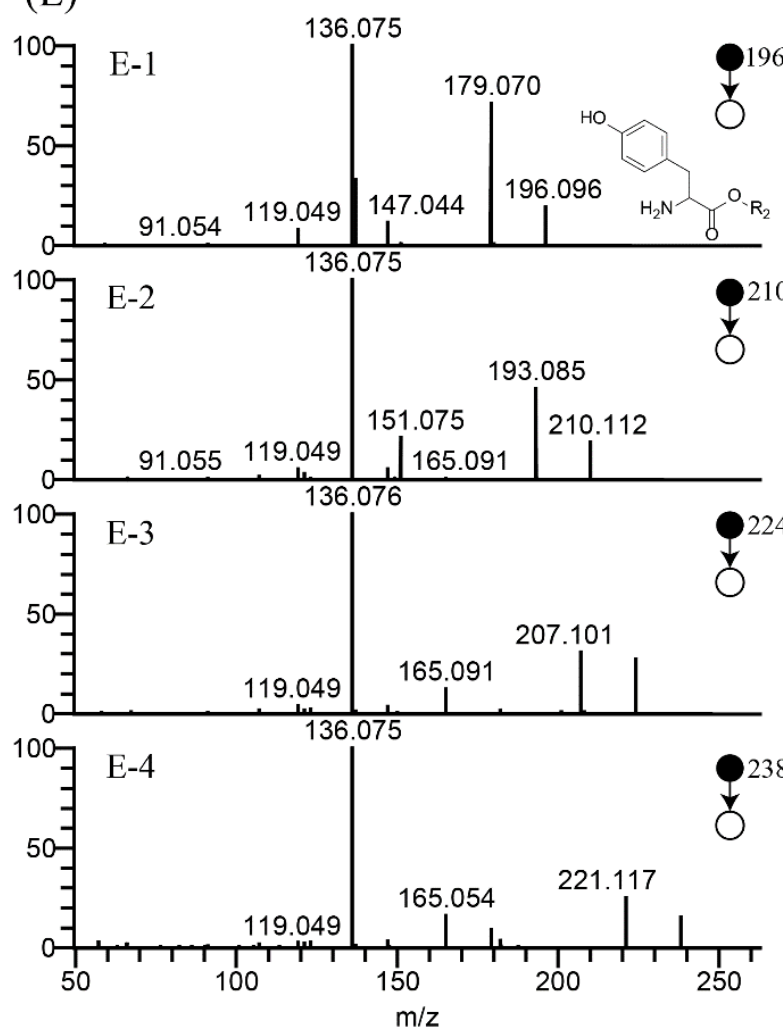

(G)

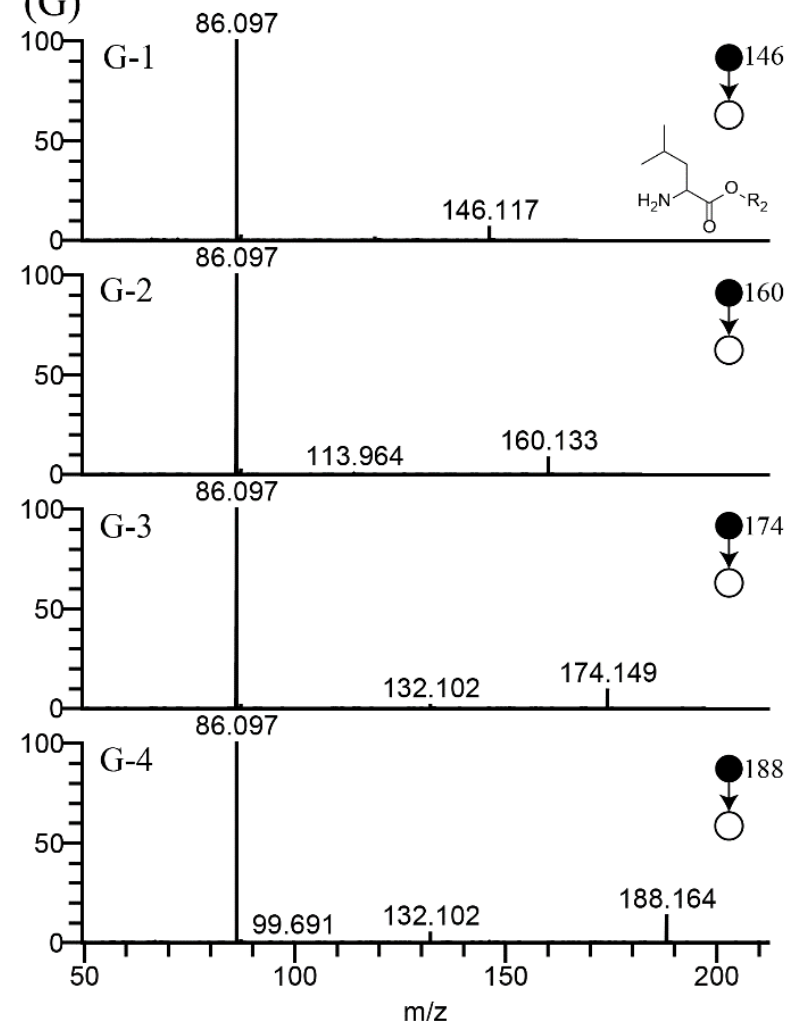

(F)

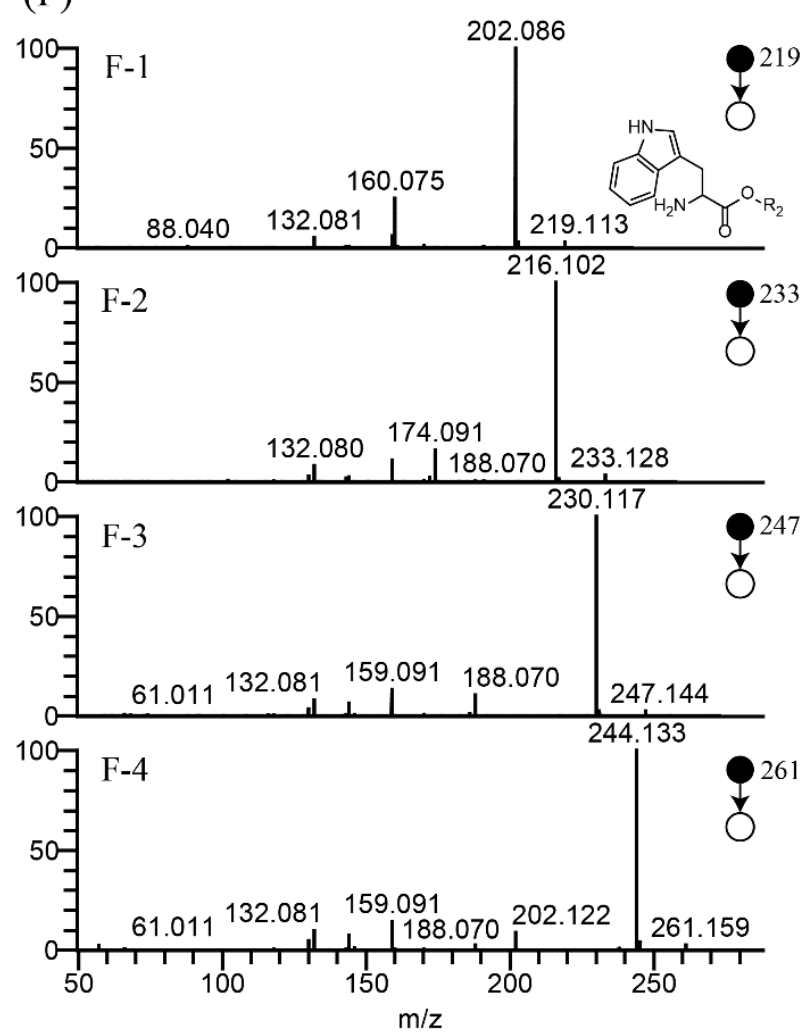

$(\mathrm{H})$

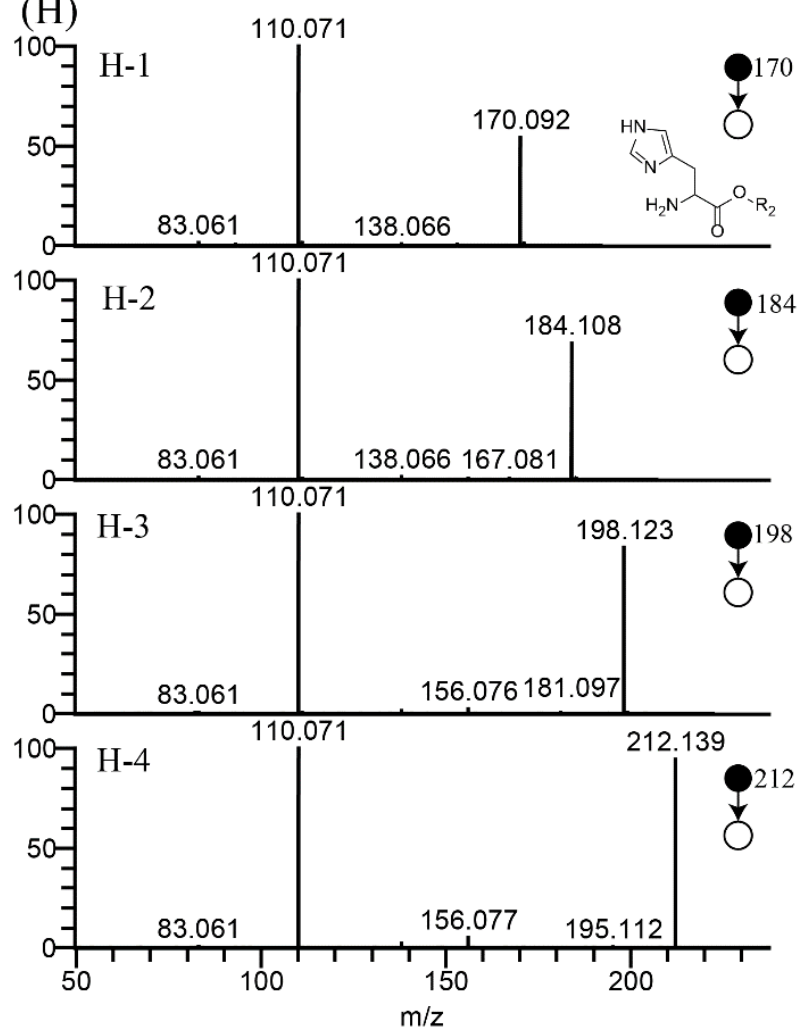

Figure S2. The MS/MS spectrum of the amino acid esterification reaction products. 

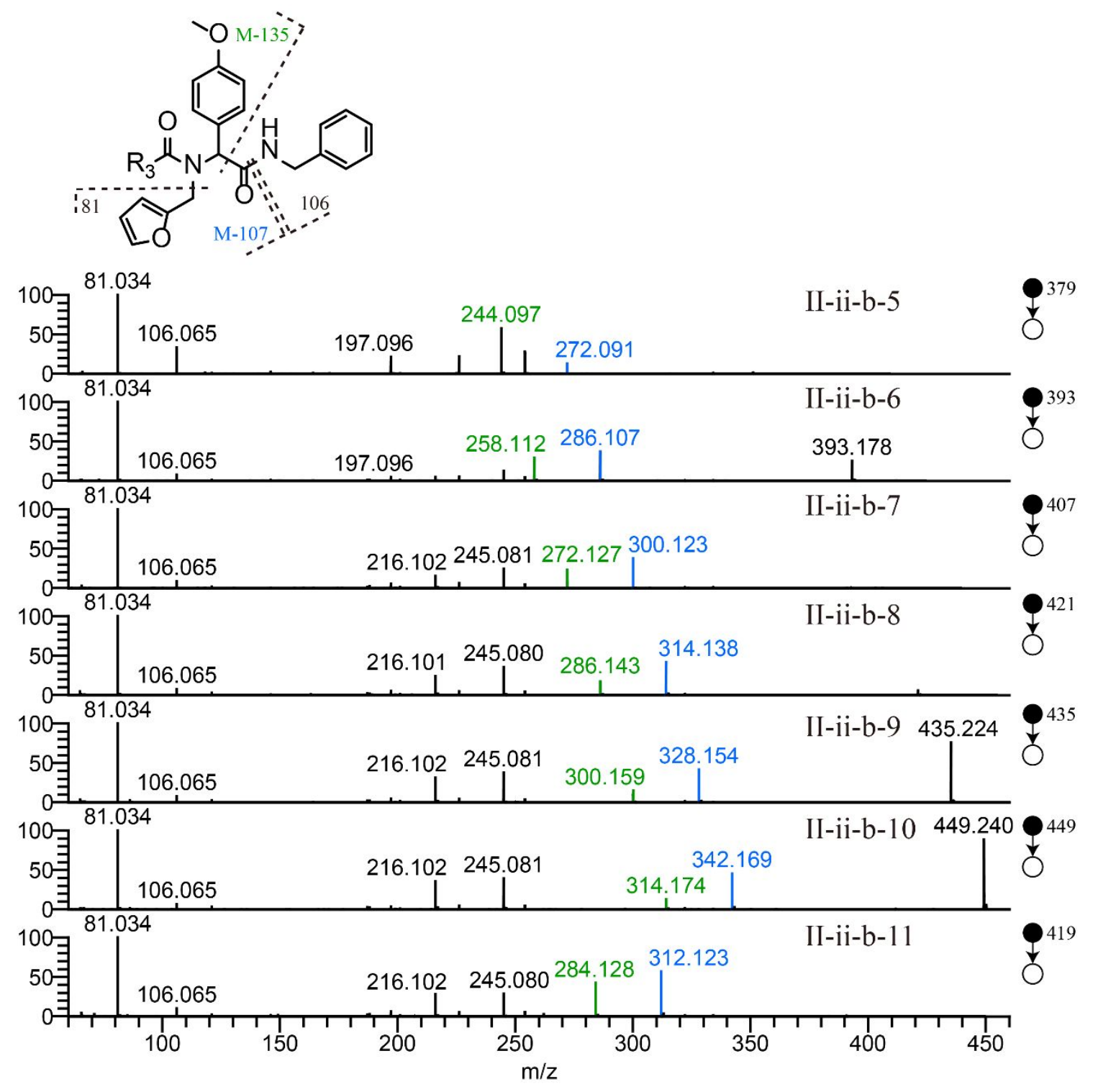

Figure S3. The structures of the fragment ions of products II-ii-b-P6 
(A)

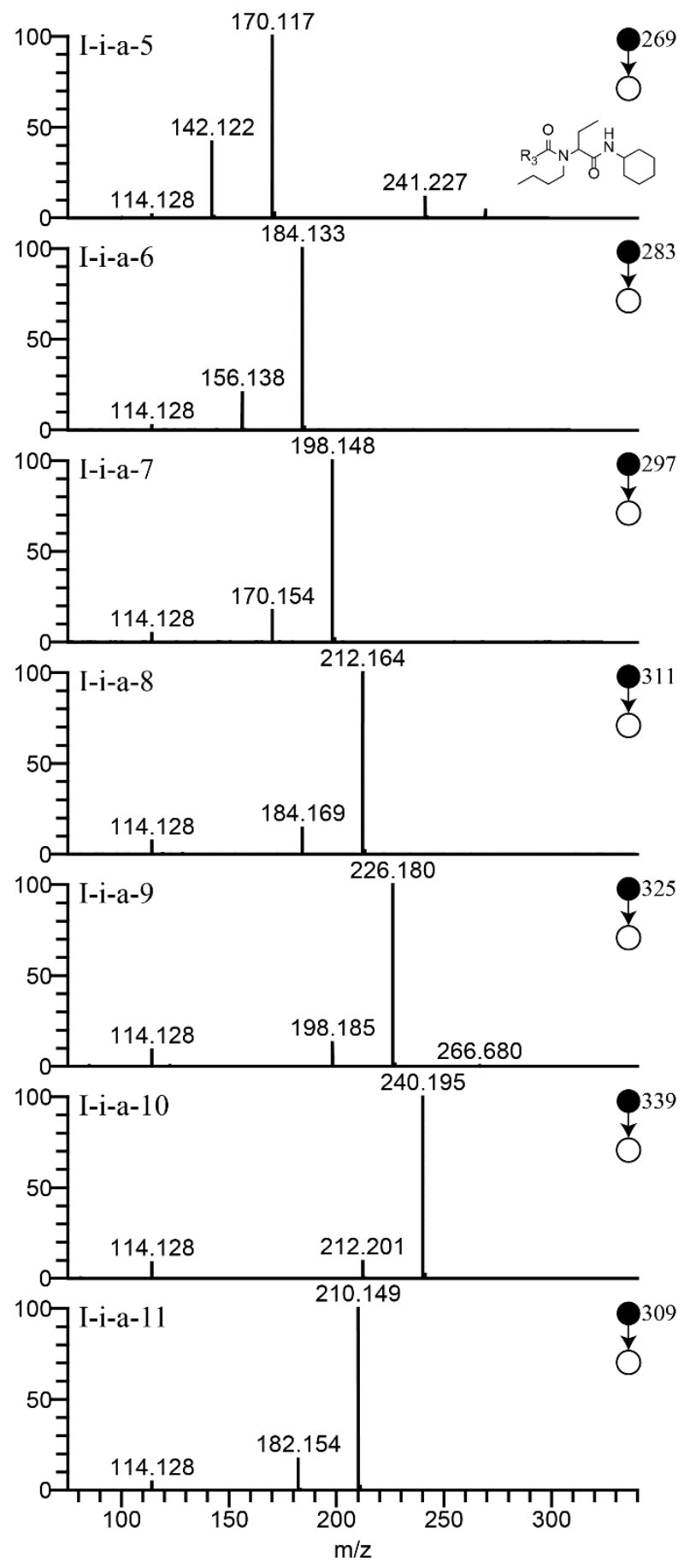

(B)

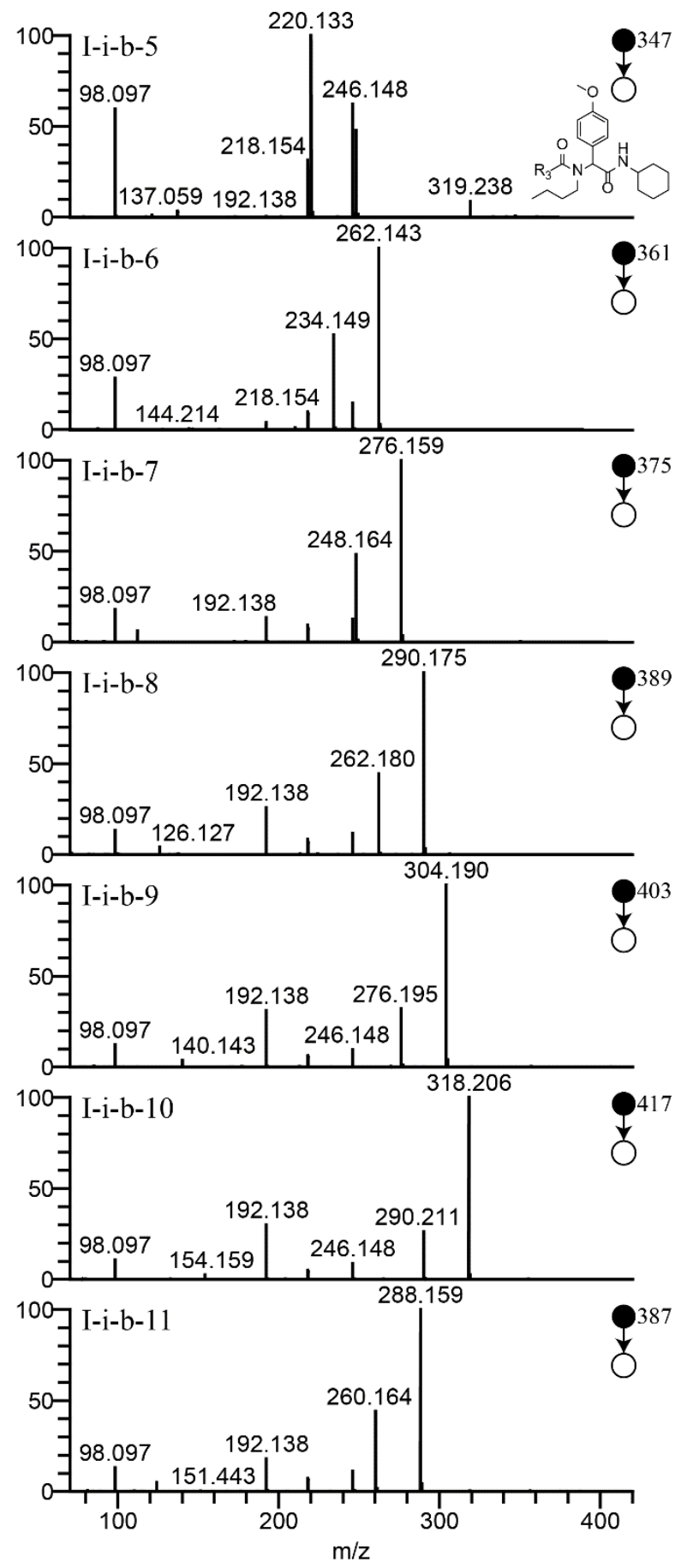


(C)

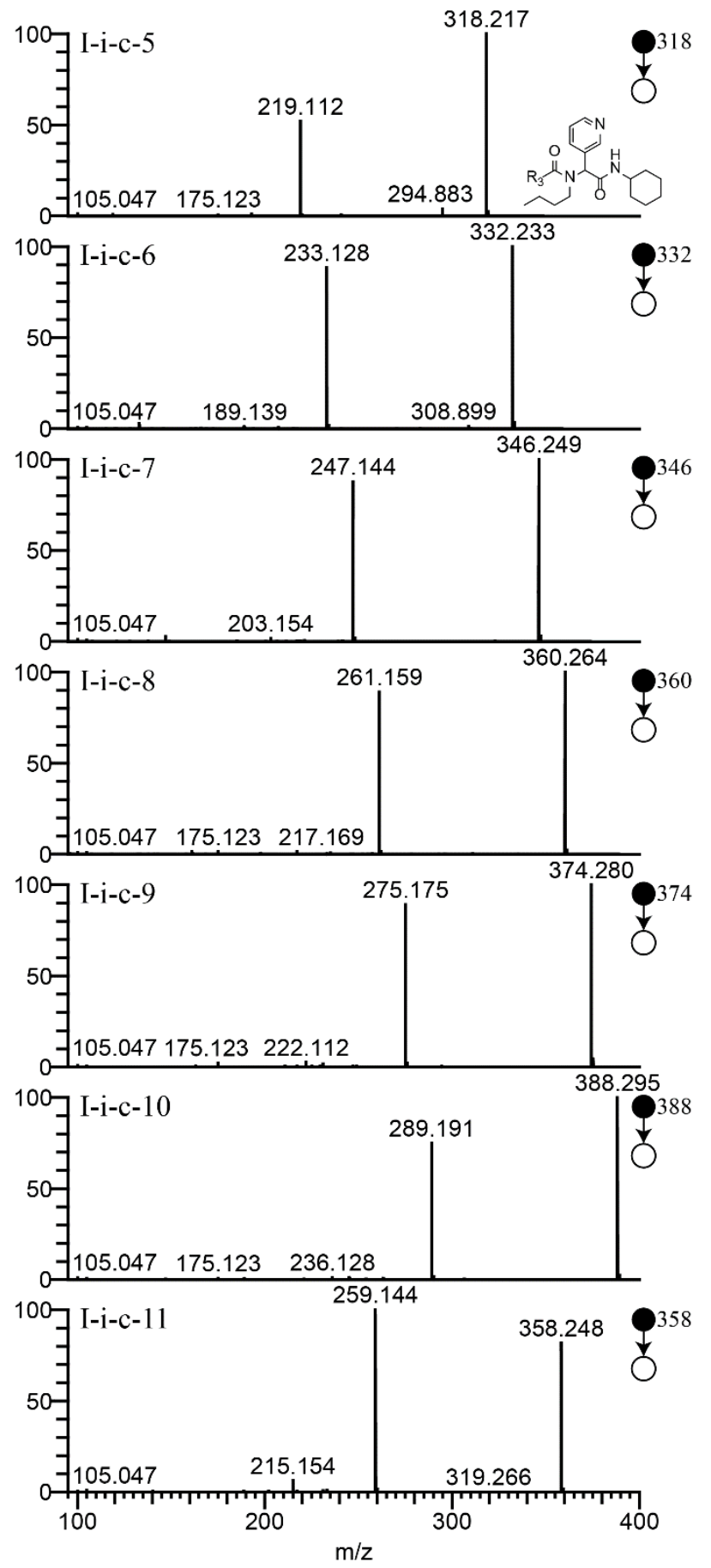

(D)

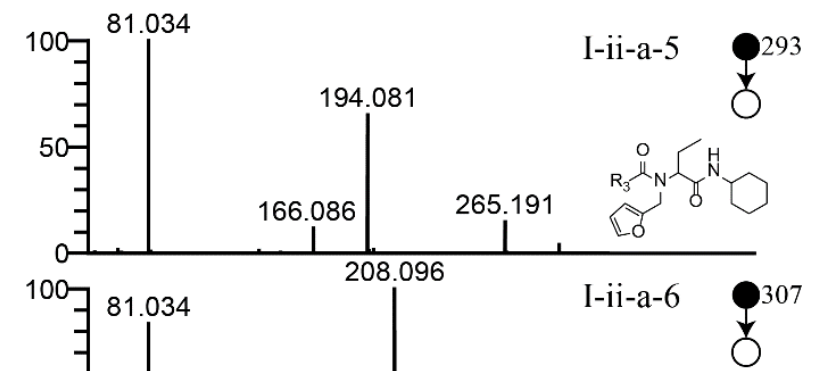


(E)

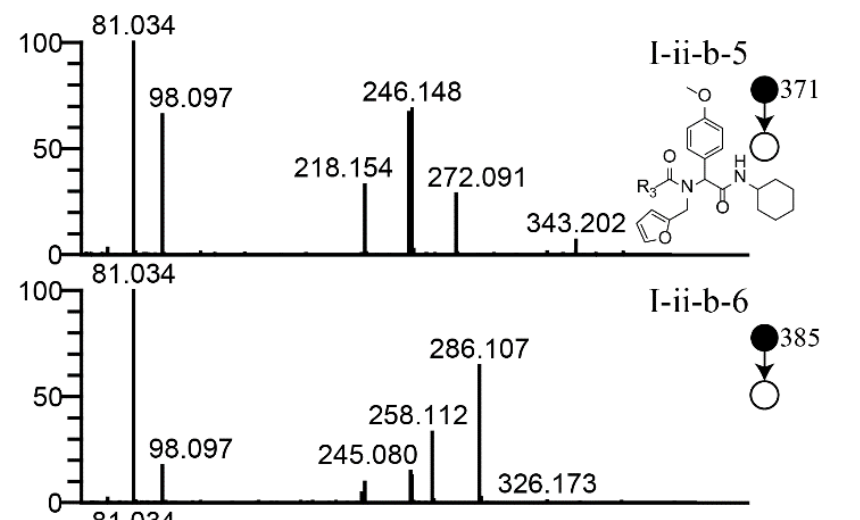

(F)

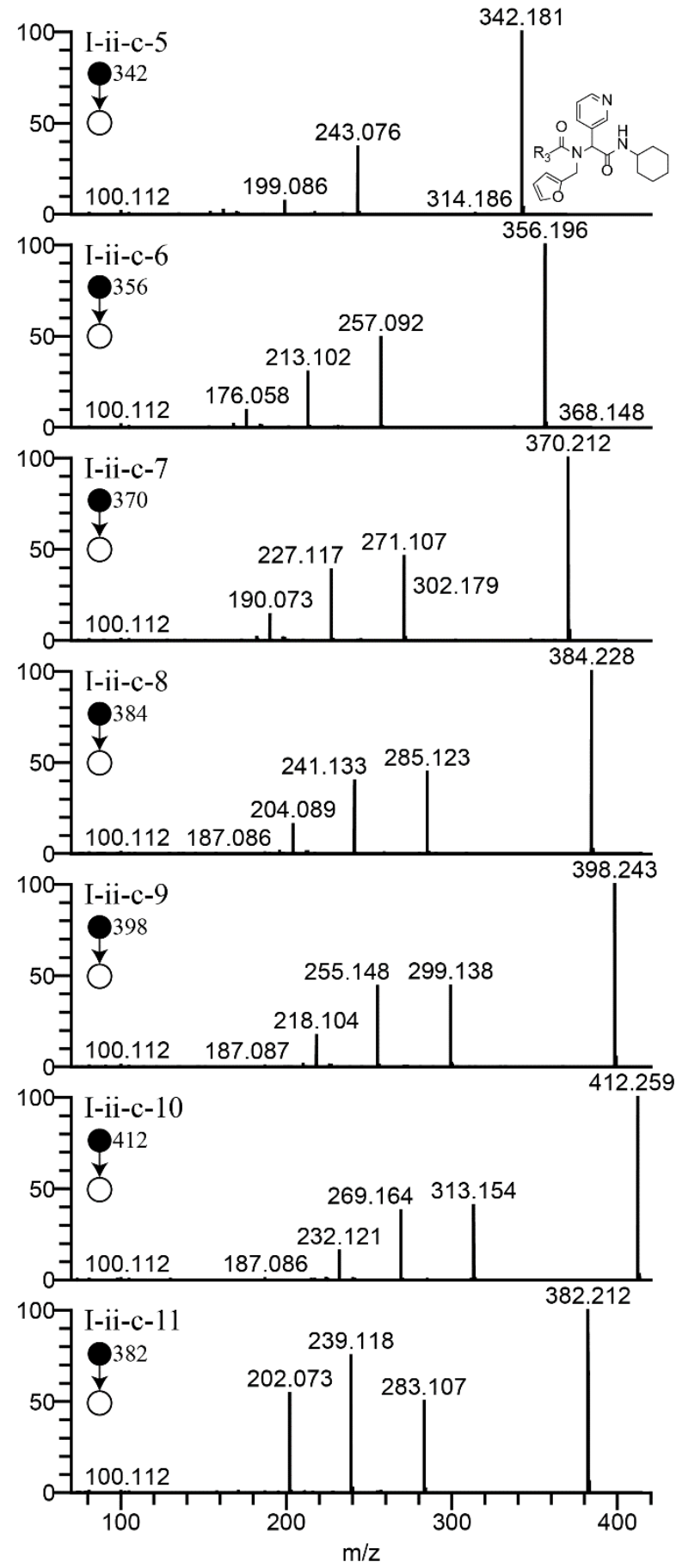


(G)

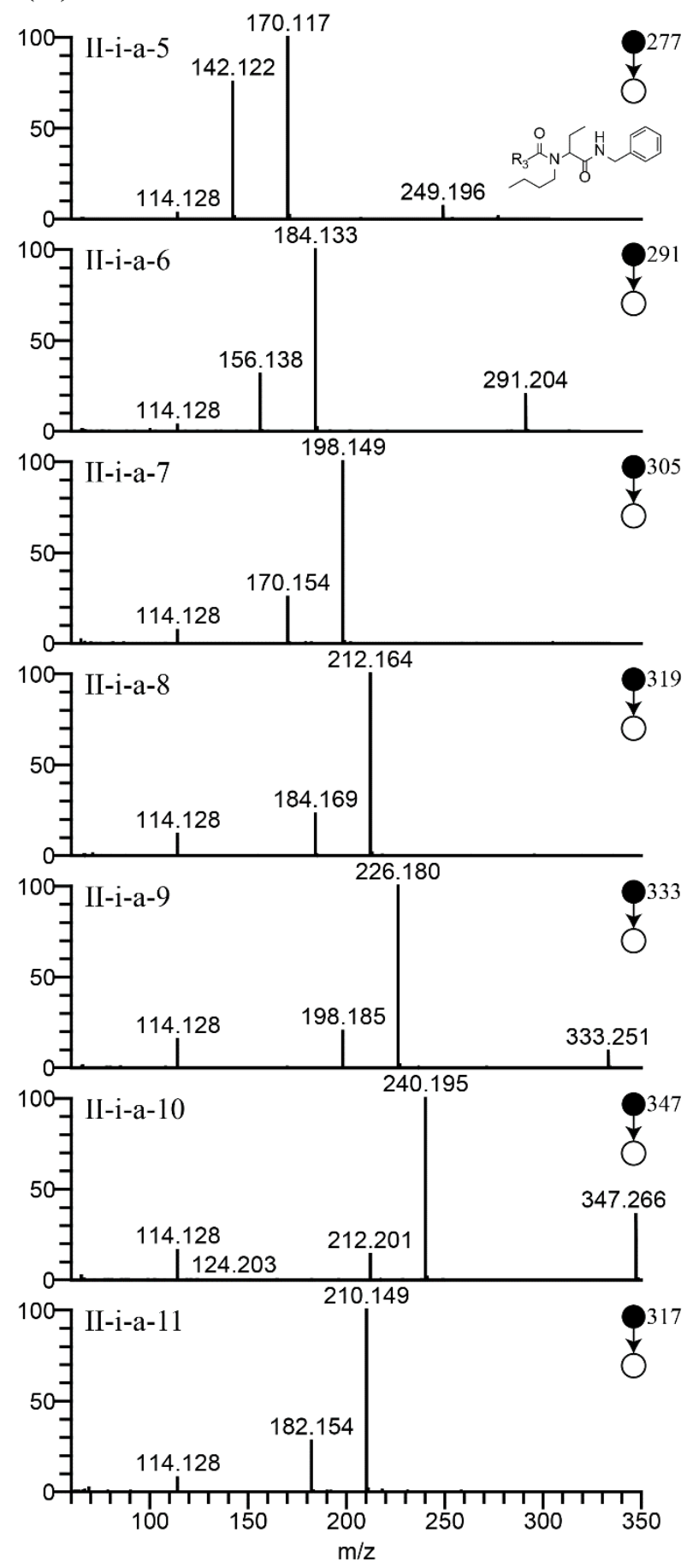

(H)

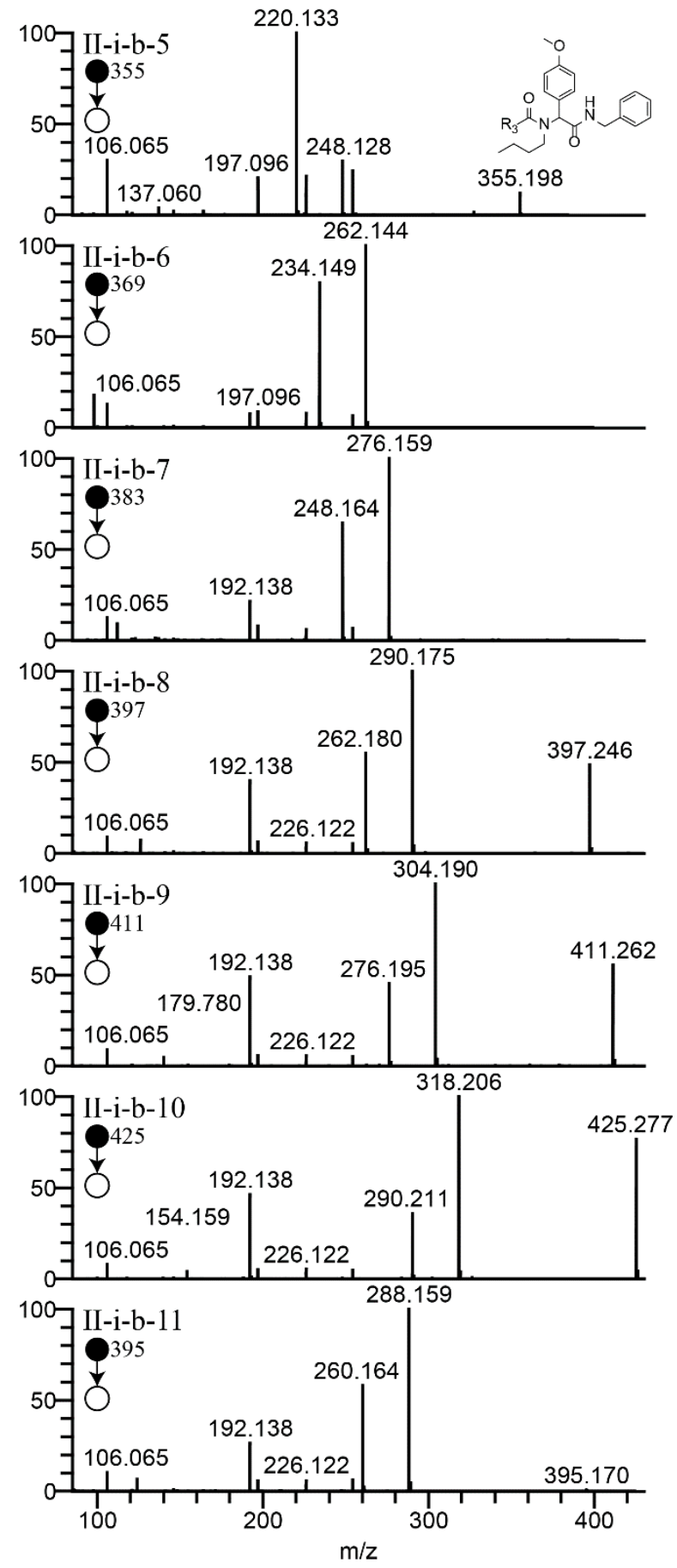


(I)

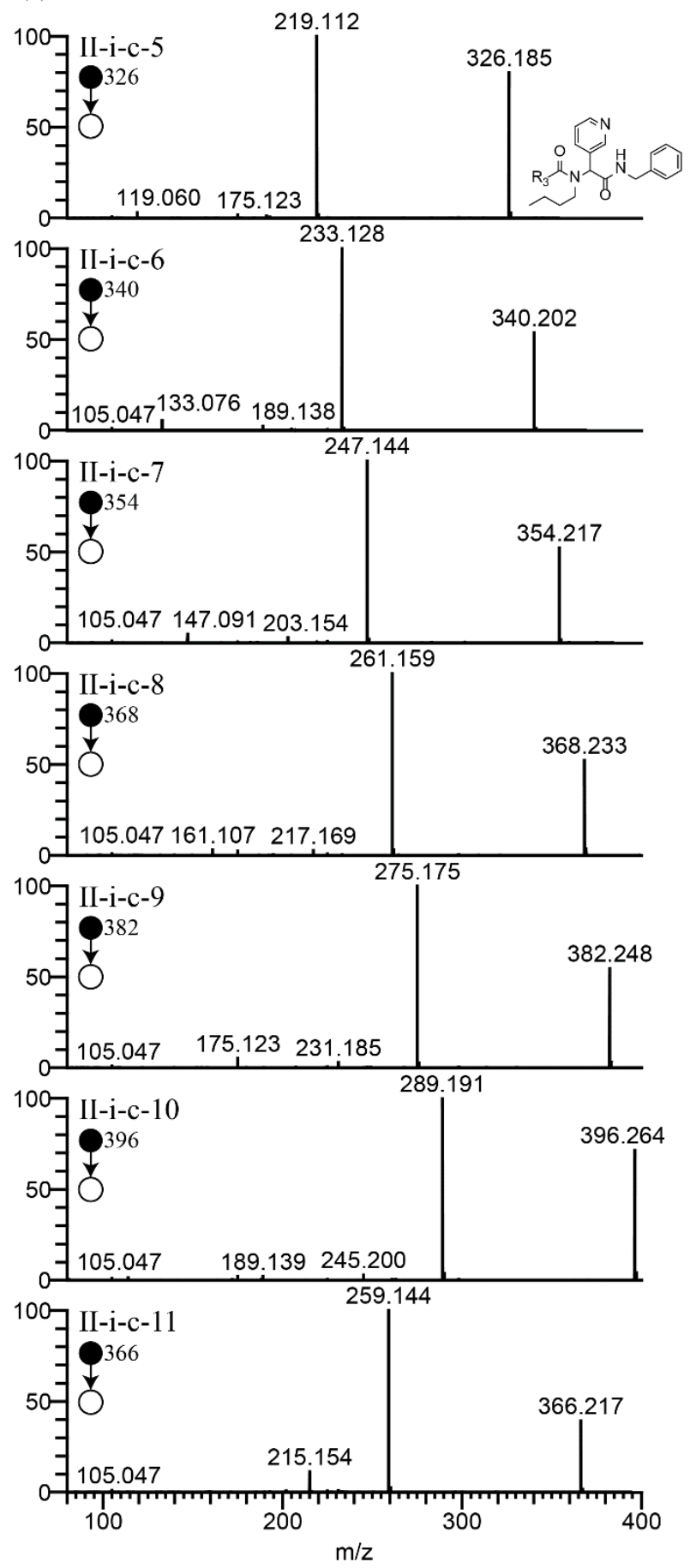

(J)

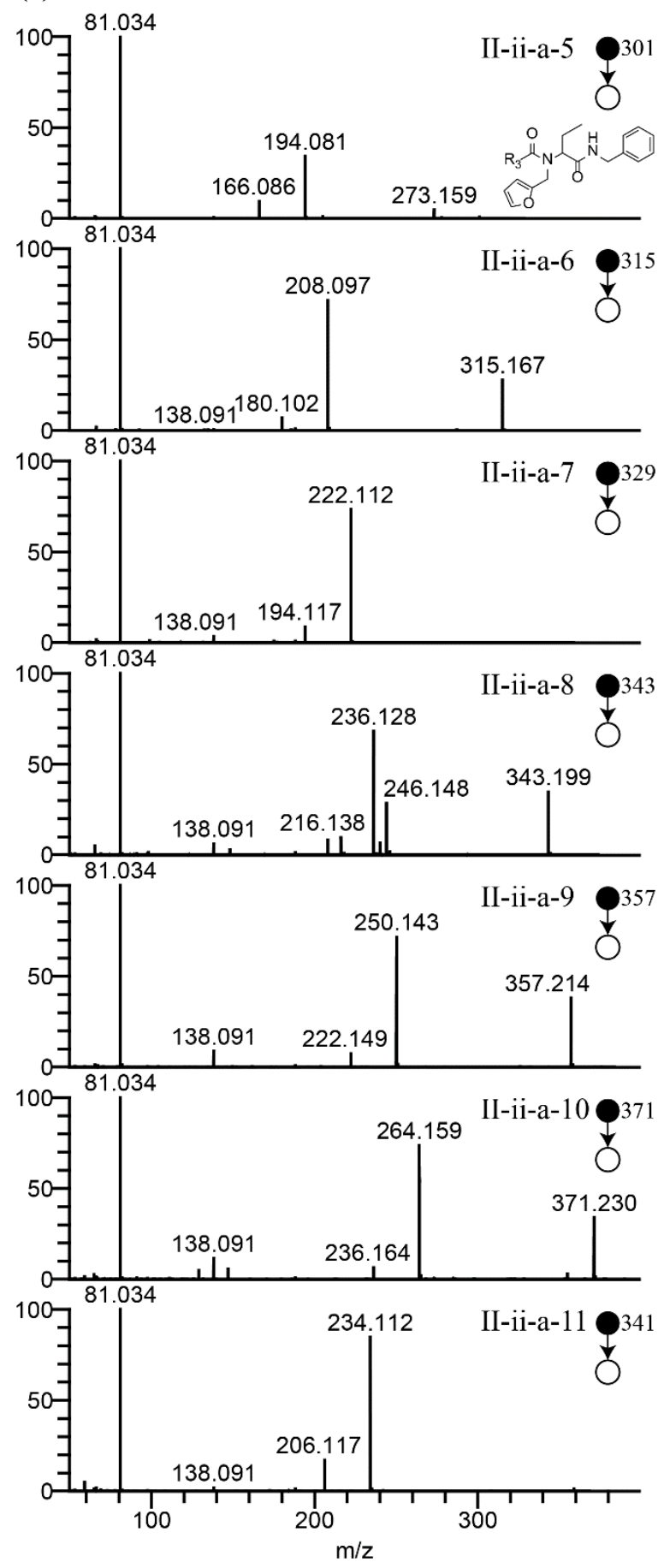


(K)

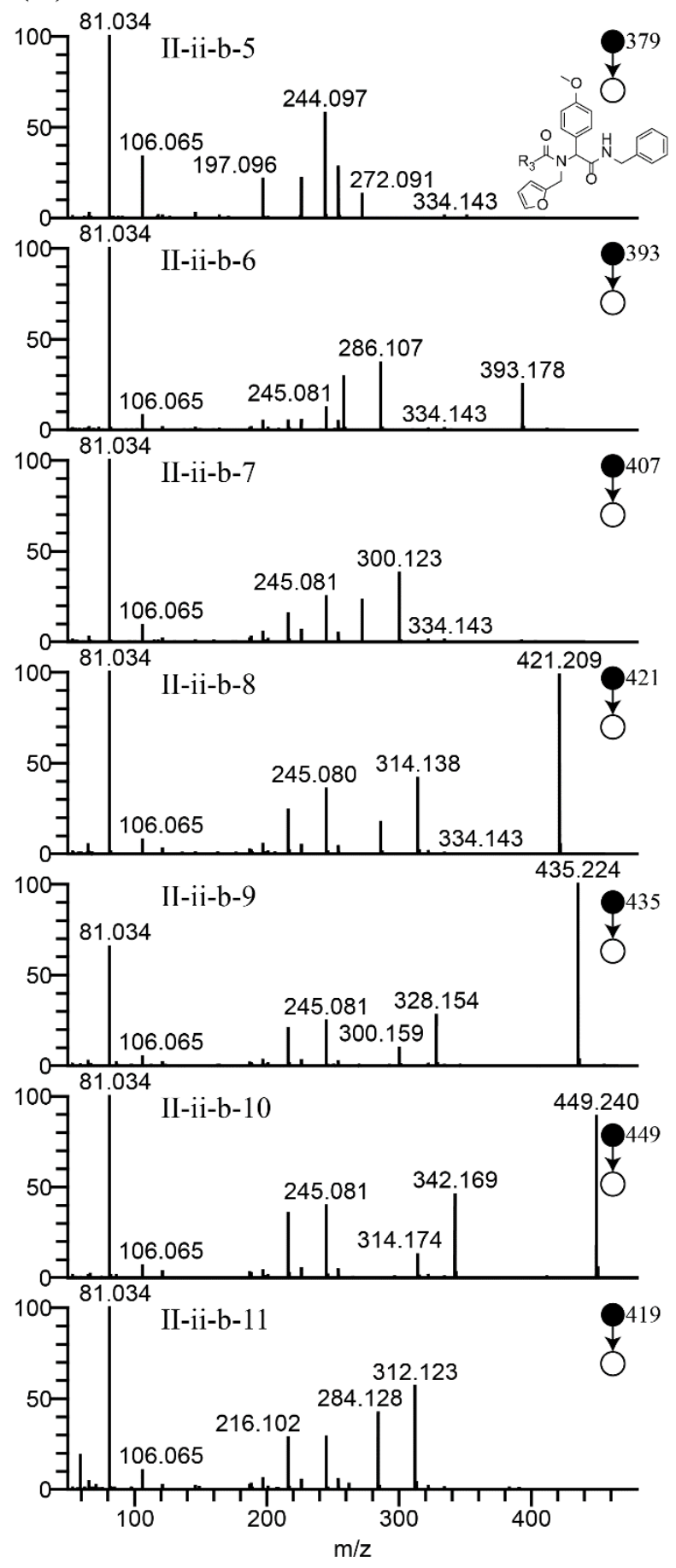

(L)
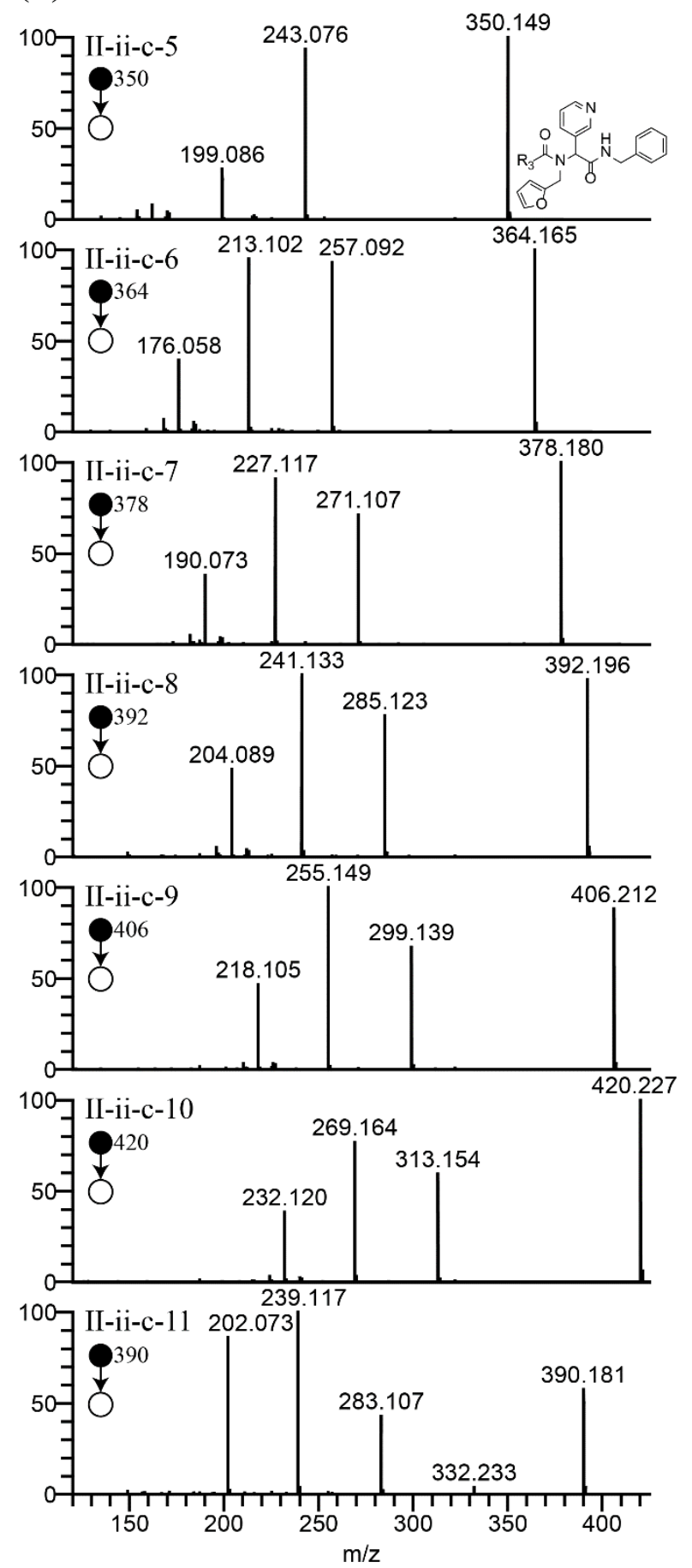

Figure S4. The MS/MS spectrum of the Ugi reaction products. 
(A)
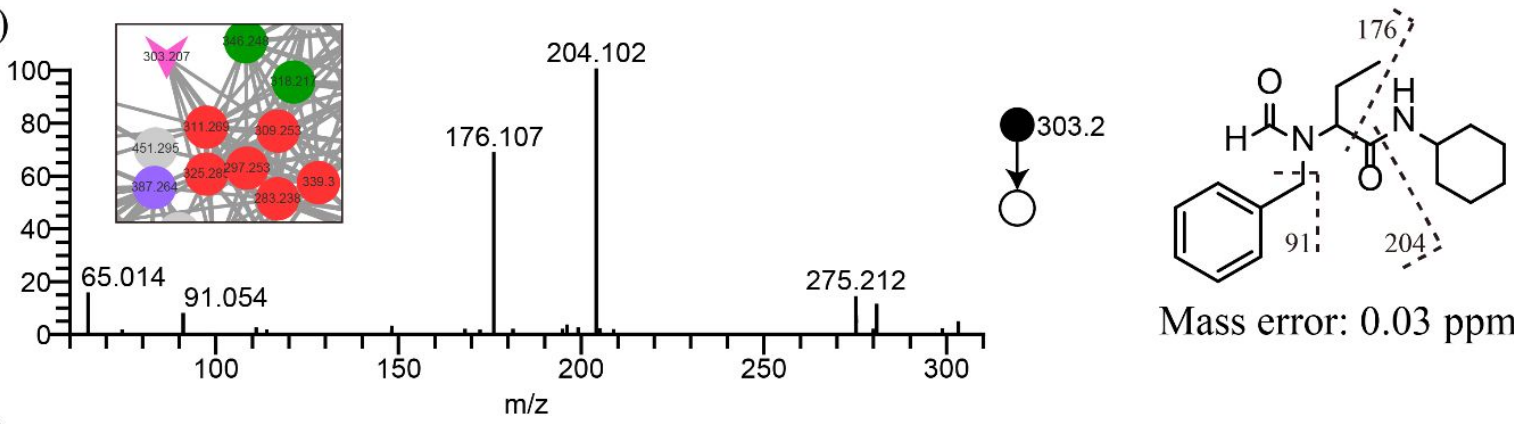

(B)
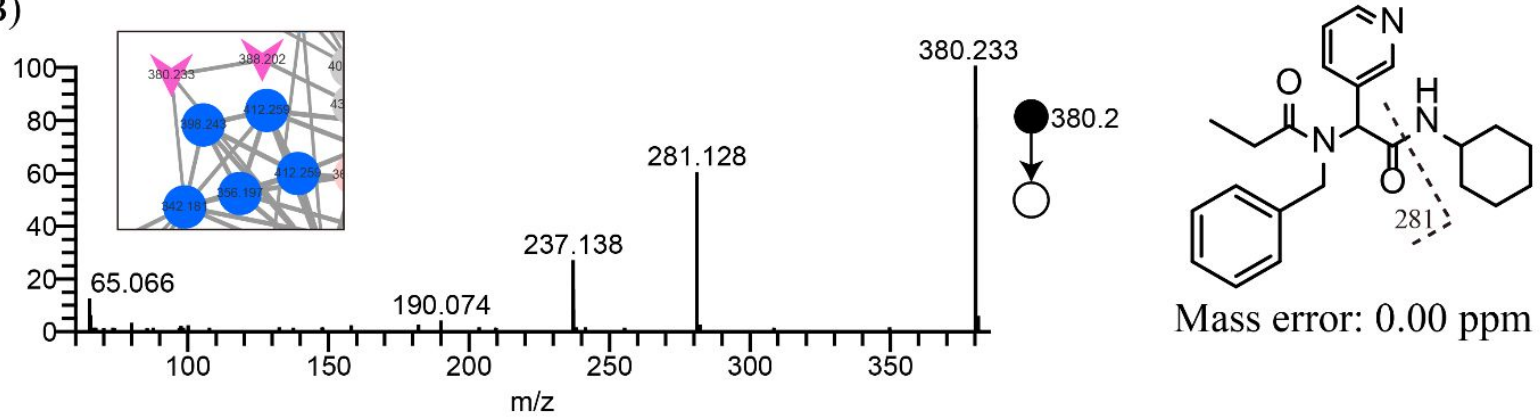

(C)

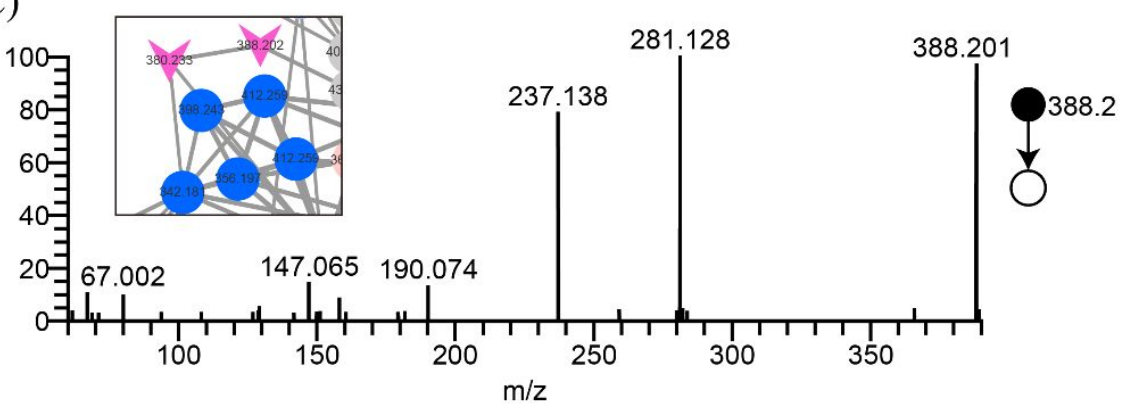

Mass error: 0.00 ppm

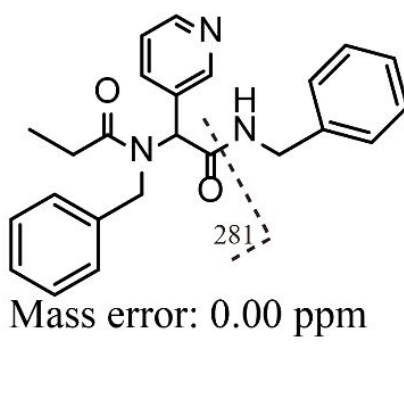

Figure S5. The MS/MS spectra of the side products and their linked nodes. The side products were labeled as pink node in the molecular networking. 
(A)

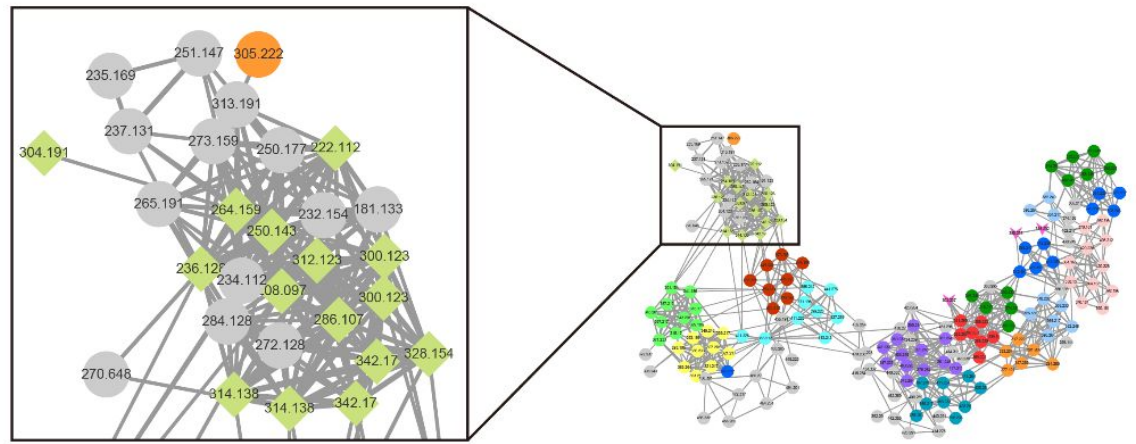

(B)
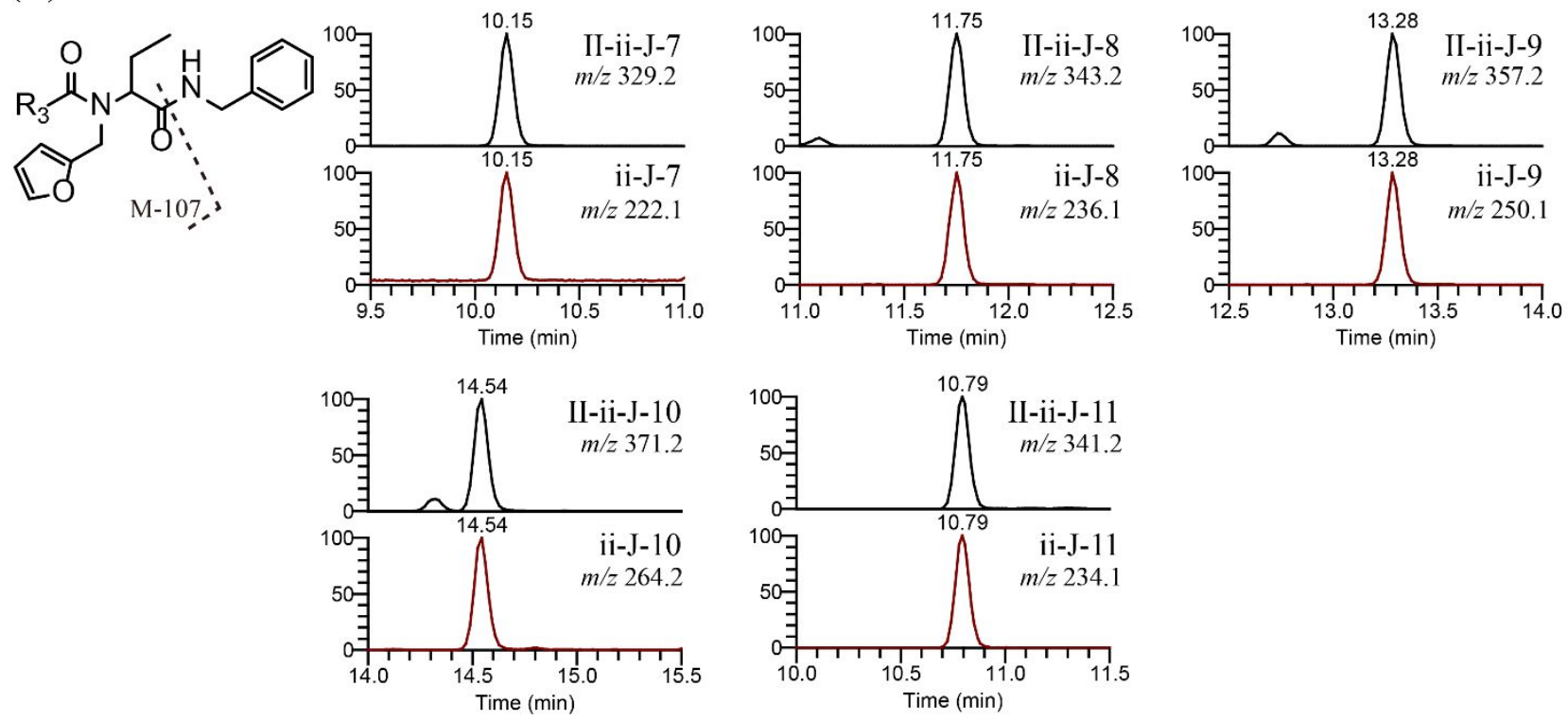

(C)<smiles>[R]C(=O)N(Cc1ccco1)C(C(=O)NCc1ccccc1)c1ccc(OC)cc1</smiles>
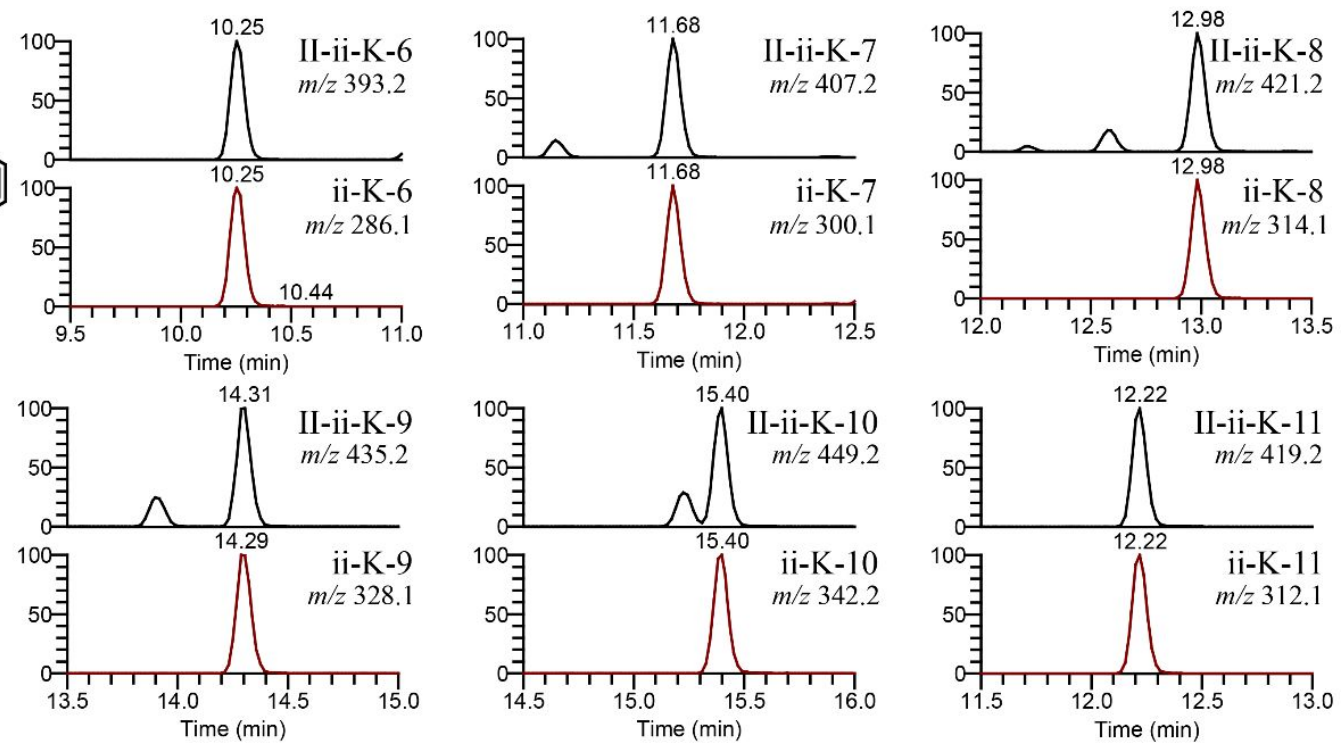

Figure S6. The extracted ion chromatogram (EIC) of the Ugi products and their in source fragmentation products that presents in the molecular networking in Figure 2D. A) II-ii-J-7 to II-ii-J-11 B) II-ii-K-6 to II-ii-J-11. 
(A) $5 \mathrm{~min}$

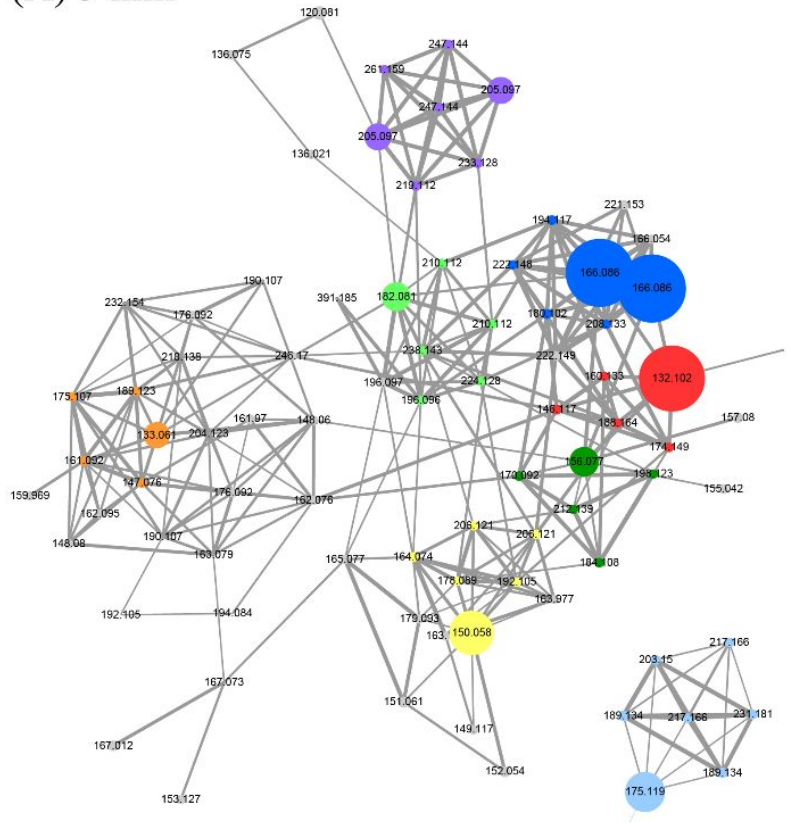

(C) 12 hour

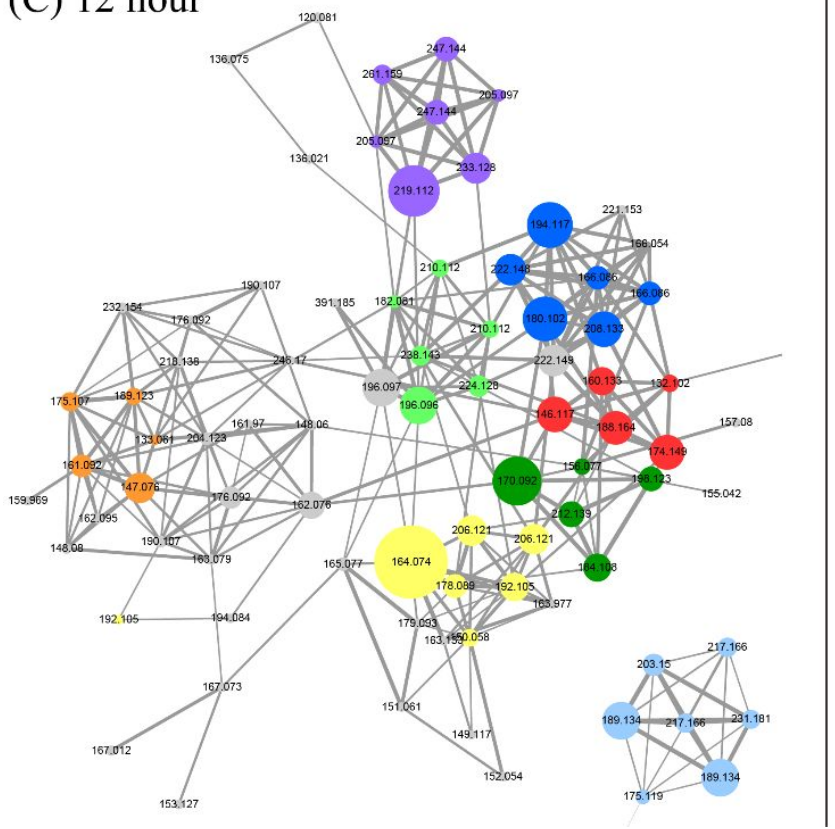

(B) 4 hour

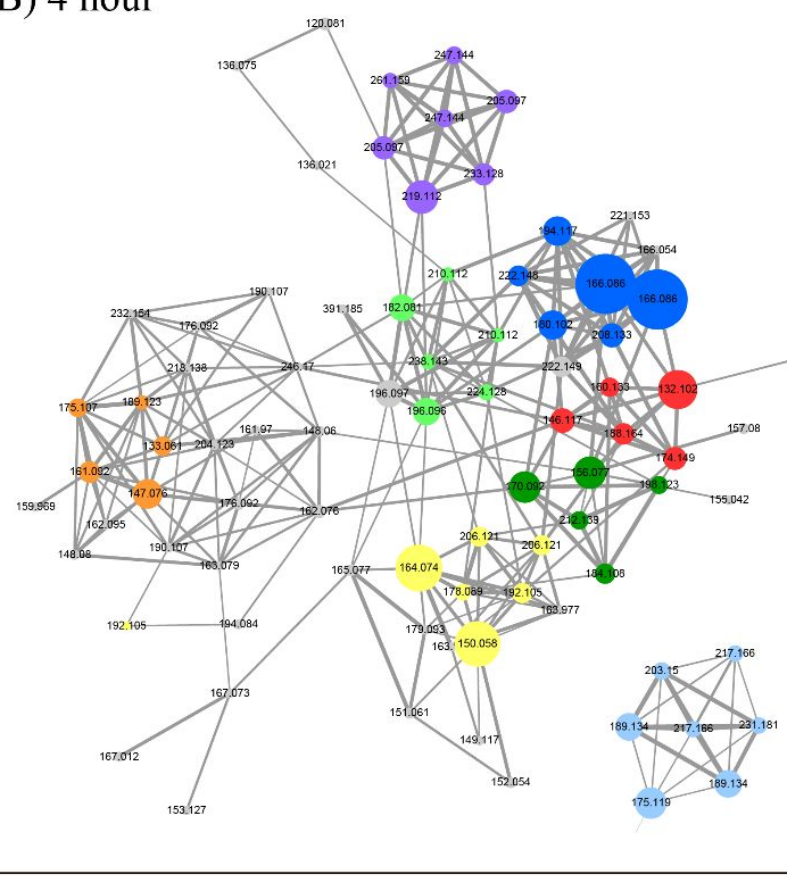

(D) 36 hour

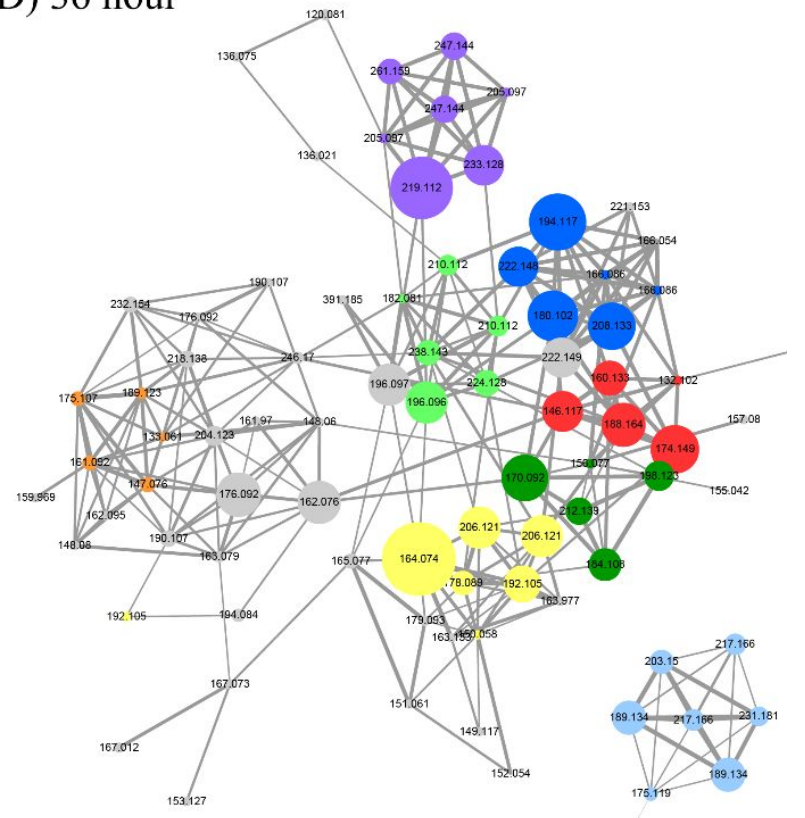

Figure S7. Time-dependent molecular networking of amino acid esterification reaction. 


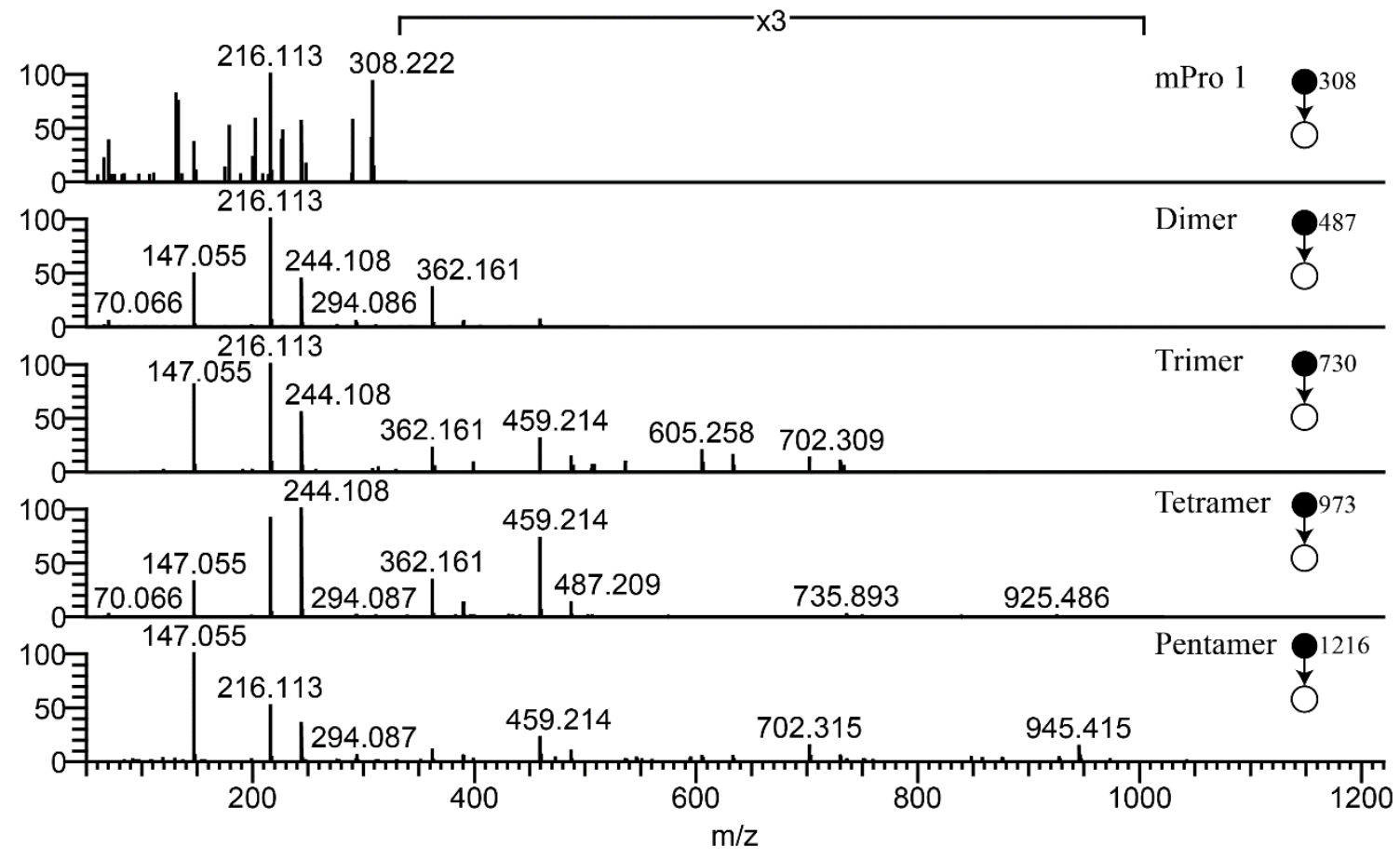

Figure S8. The MS/MS spectrum of the mPro oligomers. 